\title{
A prostacyclin agonist and an omental flap increased myocardial blood flow in a porcine chronic ischemia model
}

\author{
Shin Yajima, MD, ${ }^{\text {a }}$ Shigeru Miyagawa, MD, PhD, ${ }^{\text {a }}$ Satsuki Fukushima, MD, PhD, ${ }^{\text {a }}$ Yoshiki Sakai, BSc, ${ }^{\text {a }}$ \\ Kayako Isohashi, MD, PhD, ${ }^{\mathrm{b}}$ Tadashi Watabe, MD, PhD, ${ }^{\mathrm{b}}$ Hayato Ikeda, PhD, ${ }^{\mathrm{b}}$ Genki Horitsugi, BSc, ${ }^{\mathrm{b}}$ \\ Akima Harada, BSc, ${ }^{a}$ Ryoto Sakaniwa, $\mathrm{PhD},{ }^{\mathrm{c}}$ Jun Hatazawa, $\mathrm{MD}, \mathrm{PhD},{ }^{\mathrm{b}}$ and Yoshiki Sawa, MD, $\mathrm{PhD}^{\mathrm{a}}$
}

\section{ABSTRACT}

Objective: We hypothesized that therapeutic efficacy may be augmented by a combination of placing a sheet immersed in ONO-1301SR, a slow-release synthetic prostacyclin agonist-inducing multiproangiogenic cytokines, over the left ventricle and a pedicled omental flap in a chronic myocardial infarct heart.

Methods: A minipig chronic myocardial infarction was generated by placing an ameroid constrictor ring around the left anterior descending artery for 4 weeks. The minipigs were then assigned into 4 groups of 6 each: sham, omental flap only, ONO-1301SR only, and ONO-1301SR combined with an omental flap (combined). Four weeks after treatment, therapeutic efficacy was evaluated histologically and via several modalities used in the clinical setting.

Results: In an angiogram and pressure wire study, the combined group induced development of collateral arteries to decrease the resistance and increase the flow reserve of microvasculature in the left circumflex territory. In a ${ }^{13} \mathrm{~N}$-ammonia positron emission tomography study, the combined group displayed a prominent increase in myocardial blood flow and myocardial flow reserve in the left circumflex territory, particularly at the infarct-border region. Consequently, the combined group showed greater regional cardiac function in the left circumflex territory particularly at the infarct-border region, contributing to a greater global ejection fraction with a smaller left ventricular endosystolic volume. Pathologically, attenuated fibrosis, nonswollen myocytes, and upgraded capillary density and proangiogenic cytokines were prominent in the combined group.

Conclusions: ONO-1301SR combined with a pedicled omental flap synergistically promoted myocardial angiogenesis, leading to function recovery in a porcine chronic myocardial infarction model. ( $\mathrm{J}$ Thorac Cardiovasc Surg 2018;156:229-241)

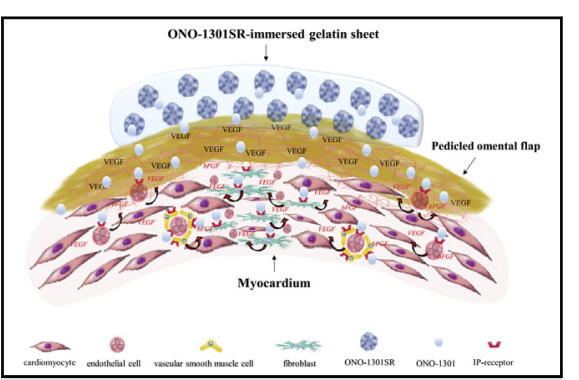

The concept of ONO-1301SR with a pedicled omental flap therapy.

\section{Central Message}

Combined treatment with ONO-1301SR and pedicle omentum produced the greatest functional recovery associated with the greatest myocardial blood flow and flow reserve in a porcine chronic MI model.

\section{Perspective}

ONO-1301SR combined with a pedicle omental flap therapy synergistically promoted myocardial angiogenesis, leading to decrease in the resistance of the microvasculature, in crease in regional MBF and MFR and improvement in regional and global cardiac function in a porcine chronic MI model. This cell-free combination therapy would be useful in enhancing myocardial angiogenesis in a chronic MI heart.

See Editorial Commentary page 242
Ischemic insults result in necrosis or apoptosis of cardiac myocytes, modulation of extracellular matrices, or failure of microvascular networks, consequently leading to left

\footnotetext{
From the Departments of ${ }^{\mathrm{a} C a r d i o v a s c u l a r}$ Surgery, ${ }^{\mathrm{b}}$ Nuclear Medicine and Tracer Kinetics, and ${ }^{\mathrm{c} P u b l i c}$ Health, Osaka University Graduate School of Medicine, Osaka, Japan.

Supported by Grants-in-Aid for Scientific Research (KAKENHI, grant No. 15K10214).

ONO-1301SR was supplied by Ono Pharmaceutical Co. Ltd, Osaka, Japan.

Received for publication Sept 8, 2017; revisions received Jan 29, 2018; accepted for publication Feb 7, 2018; available ahead of print April 5, 2018.

Address for reprints: Yoshiki Sawa, MD, PhD, Department of Cardiovascular Surgery, Osaka University Graduate School of Medicine, 2-2 Yamadaoka, Suita, Osaka 565-0871, Japan (E-mail: s-yajima@ surg1.med.osaka-u.ac.jp). $0022-5223 / \$ 36.00$

Copyright (c) 2018 by The American Association for Thoracic Surgery https://doi.org/10.1016/j.jtcvs.2018.02.086
}

ventricle (LV) remodeling, including progressive deterioration of cardiac function. ${ }^{1}$ Microvascular dysfunction, which induces persistent regional myocardial ischemia, is suggested as among the major pathologies causing LV remodeling. It is irreversible even with the latest medical or interventional approaches. ${ }^{2}$ It has recently been suggested that a regenerative approach using cell transplantation therapy upregulates myocardial expression of a variety of

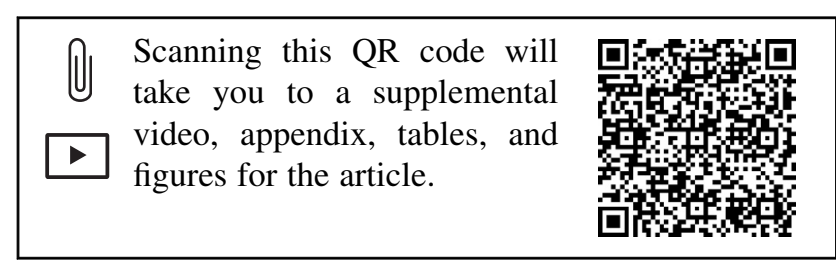



Abbreviations and Acronyms
$\mathrm{CFR}=$ coronary flow reserve
$\mathrm{CS}=$ circumferential strains
$\mathrm{CSR}=$ circumferential strain rates
$\mathrm{FGF}=$ fibroblast growth factor
$\mathrm{HGF}=$ hepatocyte growth factor
IMR = index of microvascular resistance
LAD $=$ left anterior descending artery
LCX = left circumflex artery
$\mathrm{LV}=$ left ventricle
$\mathrm{MBF}=$ myocardial blood flow
MFR = myocardial flow reserve
MI = myocardial infarction
MRI = magnetic resonance imaging
PET = positron emission tomography
RCA = right coronary artery
SDF-1 $=$ stromal cell derived factor-1
VEGF $=$ vascular endothelial growth factor

proangiogenic factors. This leads to reorganization of microvascular networks and regional myocardial blood flow (MBF) increases, consequently inducing functional recovery in chronic myocardial infarct (MI) hearts, although cell transplantation therapy is limited by the cell preparation process in clinical scenarios.

Prostacyclin is an endogenous factor that protects and regenerates damaged tissues and/or organ ${ }^{5-7}$; therefore, it may enhance regeneration in chronic pathologies. However, the use of clinically available prostacyclin analogues for treating chronic pathologic conditions is limited due to their short half-lives. A new reagent, ONO$1301 \mathrm{SR}$, is a slow-release form of ONO-1301, a unique synthetic prostacyclin agonist conjugated with lactic and glycolic acid polymer. Reports suggest that ONO-1301SR constitutively releases prostacyclin analogues to adjacent tissues for 4 weeks, indicating its therapeutic potential via slow-release delivery into a specific organ. ${ }^{8-10}$ Our laboratory demonstrated that administration of ONO1301SR into several acute MI and dilated cardiomyopathy animal models yielded proangiogenic cytokines, such as vascular endothelial growth factor (VEGF) or hepatocyte growth factor (HGF), and stromal cell derived factor-1 (SDF-1), recruiting damaged ischemic myocardium and inducing functional recovery. ${ }^{11-13}$

Furthermore, we have been developing treatments that enhance therapeutic angiogenesis in the myocardium, such as ONO-1301SR, ${ }^{12-15}$ pedicle omentum, ${ }^{16-18}$ and cell sheet. ${ }^{19-21}$ Of them, clinical availability would be prominent in ONO-1301SR only, which in contrast is therapeutically limited by the nature of the myocardium. In the myocardium, in which endothelial cells, fibroblasts, or vascular smooth muscle cells are severely damaged, therapeutic effects of ONO-1301SR would be severely limited.

Pedicle omentum is a proangiogenic tissue that enhances therapeutic angiogenesis in the myocardium. ${ }^{22-24}$ However, the omentum alone is insufficient to produce clinically identifiable therapeutic benefits, because the positive effects of the omentum are counterbalanced by surgical damage in retrieval of the omentum from the abdomen. We recently reported that a skeletal myoblast sheet ${ }^{16,18}$ or induced pluripotent stem cell-derived cardiomyocyte sheet ${ }^{17}$ covered with a pedicled omental flap yielded further cardiac functional recovery, including increased angiogenesis and attenuated fibrosis in ischemic cardiomyopathy models. We believe that a combination of ONO-1301SR and pedicle omentum would compensate for each option's drawbacks to achieve clinically identifiable therapeutic benefits, and hypothesized that ONO-1301SR covered with a pedicled omental flap over the LV surface could be synergic to augment proangiogenic effects on a chronic MI heart.

\section{METHODS}

The institutional ethics committee approved all experimental procedures. Animal care was conducted humanely in compliance with the principles of laboratory animal care. ${ }^{25}$ We took care of the animals in a controlled nonstressed environment for at least a week before the study to avoid possible confounding problems related to constructive myocardial preconditioning.

\section{Preparation of ONO-1301SR}

ONO-1301SR (Ono Pharmaceutical Co, Ltd, Osaka, Japan) is a polylactic acid to glycolic acid ratio of 50:50-polymerized form of ONO-1301 designed to achieve a sustained-release system. ${ }^{26}$ It is a synthetic prostacyclin receptor agonist lacking typical prostanoid structures, including a 5-membered ring and allylic alcohol, which is rapidly metabolized by 15-hydroxyprostaglandin dehydrogenase in vivo. ${ }^{27}$ In addition, ONO1301 has a 3-pyridine radical to exert thromboxane A2 synthase inhibitory activity that induces an intrinsic prostaglandin I 2 synthesis-promoting effect to augment prostacyclin receptor agonistic activity. ${ }^{27}$ ONO-1301 and polylactic co-glycolic acid were dissolved in dichloromethane. The dissolved polymer was added to polyvinyl alcohol aqueous solution to form an oil-in-water emulsion. Then, dichloromethane was evaporated by stirring. After centrifugation and washing, YS-1402 was isolated using lyophilization. ${ }^{28}$

\section{Study Protocol}

The study protocol is shown in Figure E1, A. Göttingen minipigs weighing 20 to $25 \mathrm{~kg}$ (Ellegaard, Dalmose, Denmark) were anesthetized, endotracheally intubated, and mechanically ventilated. A minipig chronic MI model was generated by placing an ameroid constrictor ring (MRI-2.50TI; Research Instruments NW Inc, Lebanon, Ore) with an internal diameter of $4.0 \mathrm{~mm}$ around the proximal portion of the left anterior descending artery (LAD) through the left fourth intercostal space. Four weeks after ameroid placement, cardiac magnetic resonance imaging (MRI) was performed followed by random assignment of the minipigs into 4 treatment groups (all $\mathrm{n}=6$ ): saline alone (sham group), saline combined with pedicled omental flap (OM group), saline-dissolved ONO-1301SR (ONO group), and salinedissolved ONO-1301SR combined with a pedicled omental flap (combined group). 
Via a median sternotomy approach under general anesthesia, 2 pieces of $20 \times 60 \times 7$-mm absorbable gelatin compressed sponge (Gelfoam; Pfizer, New York, NY) with saline immersed with or without $3 \mathrm{mg} / \mathrm{kg}$ ONO1301SR were placed on the anterolateral surface of the LV. Then, $5 \mathrm{~mL}$ fibrin glue (Beriplast P; CSL Behring, King of Prussia, Pa) was sprayed over the epicardially placed sponge (Figure E1, B). A pedicled omentum was retrieved from the peritoneal space into the mediastinal space, preserving the arch structure of the gastroepiploic artery and covering the LV surface totally (Figure E1, C). For combined treatment, a pedicled omental was retrieved to cover the LV surface and an ONO-1301SR-immersed gelatin sheet was placed (Video 1).

Four weeks after treatment ( 8 weeks after ameroid placement), the minipigs were examined using electrocardiogram-gated MRI, ${ }^{13} \mathrm{~N}$-ammonia positron emission tomography (PET), and fluoroscopy-guided pressure wire study under general anesthesia, followed by humane sacrifice by intravenous administration of potassium-based solution and harvest of cardiac tissue for histologic and immunobiologic analysis. Normal minipigs were used as controls. Only 1 pig was lost in the OM group 27 days after treatment. Postmortem suggested the cause of death was congestive cardiac failure. All experiments were performed in a blinded manner.

Definition of myocardial territory and region, and detailed methods of fluoroscopy-guided coronary angiography and pressure wire study, proto$\mathrm{col}$, and data analysis of ${ }^{13} \mathrm{~N}$-ammonia PET and data acquisition, featuretracking analysis by cardiac MRI, histologic analysis, and real-time polymerase chain reaction are described in Appendix E1.

\section{Statistical Analysis}

JMP software version 12 (SAS Institute, Inc, Cary, NC) was used for statistical analysis. Continuous values are presented as median (interquartile range). The analyses were performed using nonparametric methods because sample sizes were too small to determine a normal or skewed distribution. Between-group differences were compared using Kruskal-Wallis analysis with a Mann-Whitney $U$ test ad hoc analysis.

\section{RESULTS}

All numbers (median [interquartile range]) and $P$ values are detailed in Table E1.

\section{Development of a New Artery Network in the Left Circumflex Artery Territory With Combined Treatment}

Treatment-inducing remodeling of the coronary artery branch network was assessed using fluoroscopy-based angiogram and pressure wire study. The proximal LAD was totally occluded in all subjects, whereas the collateral arteries dominated from the left circumflex artery (LCX) territory as compared to the right coronary artery (RCA) territory in all groups (Figure 1, $A$ ). The catheter angiogram revealed that collateral arteries (quantified by the Rentrop score) in the LCX territory in the combined group were significantly greater than the sham and OM groups, whereas there was no significant difference between the ONO and combined groups. On the other hand, there was no significant difference in the collateral arteries of the RCA territory among the 4 groups (Figure 1,B).

The index of microvascular resistance (IMR) in the LCX territory in the combined and ONO groups was significantly smaller than in the sham and OM groups, whereas there was no significant difference between the ONO and combined groups. The IMR in the RCA territory among the 4 groups was not significantly different (assessed by pressure wire study) (Figure 1, C). The combined group displayed a significantly greater coronary flow reserve (CFR) in the LCX territory, but not in the RCA territory. In the LCX territory, the CFR in the sham, OM, and ONO groups was significantly smaller than in the normal LV, whereas the CFR in the combined group was not different from the normal LV and was significantly greater than in the sham, $\mathrm{OM}$, and ONO groups.

Vascular connection between the coronary arteries and the gastroepiploic artery was evaluated in the OM group specimens. The combined group manifested vascular communication between the omentum and myocardium, as confirmed by immunohistochemical and histologic ink staining (Figure 2, $A$ and $B$ ). The combined group displayed a decreased IMR and increased CFR of the gastroepiploic artery before and after the occlusion of the LCX compared with those in the OM group (Figure 2, C).

\section{Preserved Myocardial Blood Flow and Flow Reserve in the Border Area With Combined Treatment}

Global, territorial, and regional MBF, and myocardial flow reserve (MFR) (assessed by a ${ }^{13} \mathrm{~N}$-ammonia myocardial perfusion PET study 4 weeks after treatment) were compared between the 4 treatment groups and normal LV (Figure 3, A). Global MBF in the combined group, but not the other 3 groups, was not significantly different from the normal LV (Figure 3, B). In addition, the MBF of each territory in the combined group, but not the other 3 groups, was not significantly different from the normal LV (Figure 3, C). Furthermore, the combined group displayed a significantly greater MBF of the infarct-border region than the sham group, whereas the MBF of each territory in the combined group was not significantly different from the normal LV (Figure 3, D).

Consistently, global MFR in the combined group was significantly greater than in the sham group and was not significantly different from the normal LV (Figure 4). In addition, the combined group displayed a significantly greater MFR of the LCX and RCA territories and infarctborder region than the sham group. MFR of the LAD, LCX, and RCA territories and the infarct, infarct-border, and infarct-remote regions in the combined group were not significantly different from the normal LV. MBF and MFR in the OM and ONO groups were not significantly different from the sham group.

\section{The Greatest Functional Recovery With Combined Treatment}

The global and regional function of the LV was assessed using cardiac MRI 4 weeks after treatment. All subjects except the normal ones showed typical features of anteroseptal MI, such as a thin wall with 

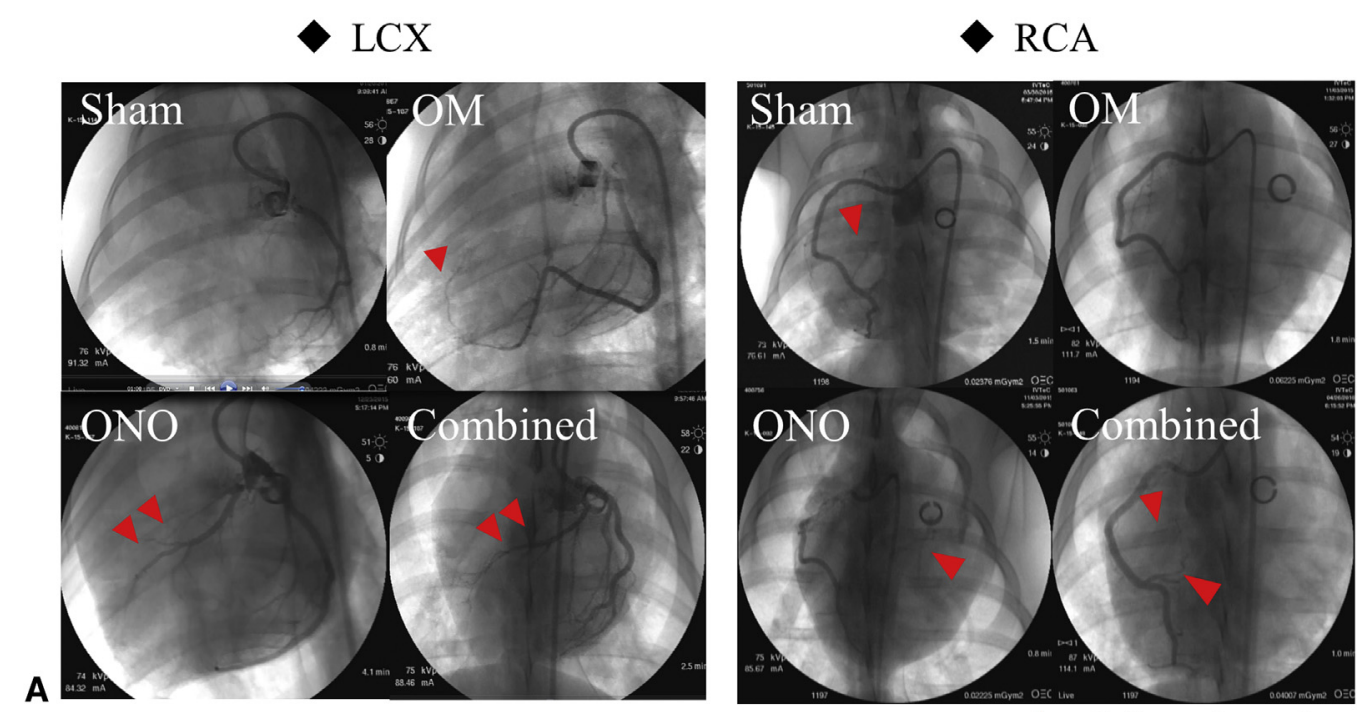

$\Delta:$ Collateral arteries

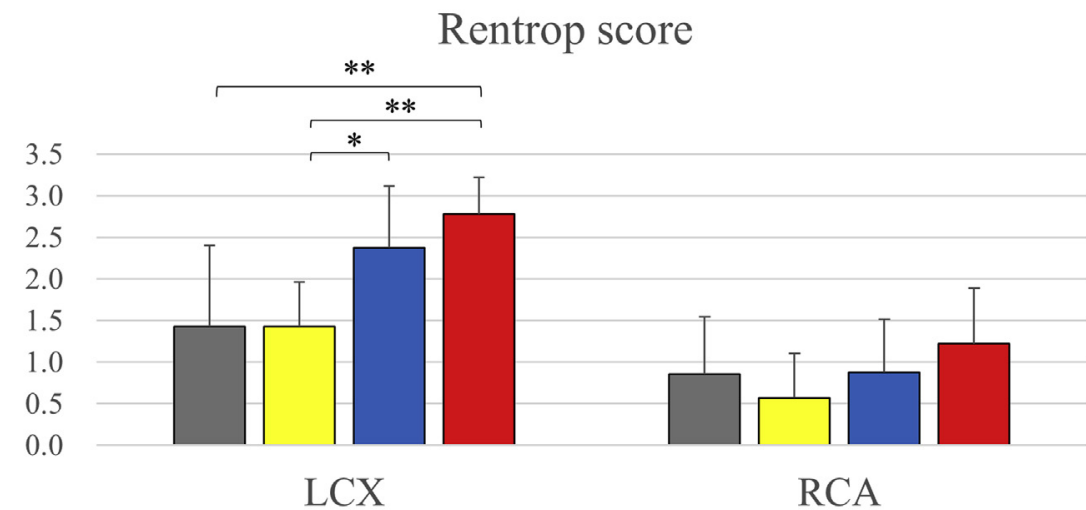

B

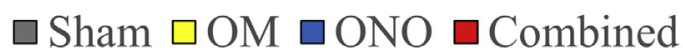

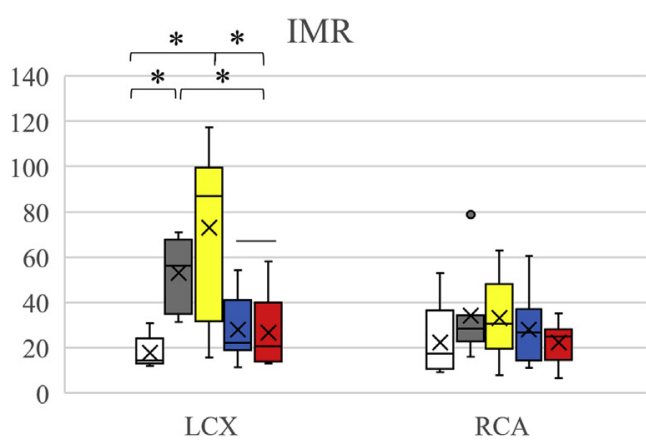

C $\square$ Normal $\square$ Sham $\square$ OM $\square$ ONO $\square$ Combined

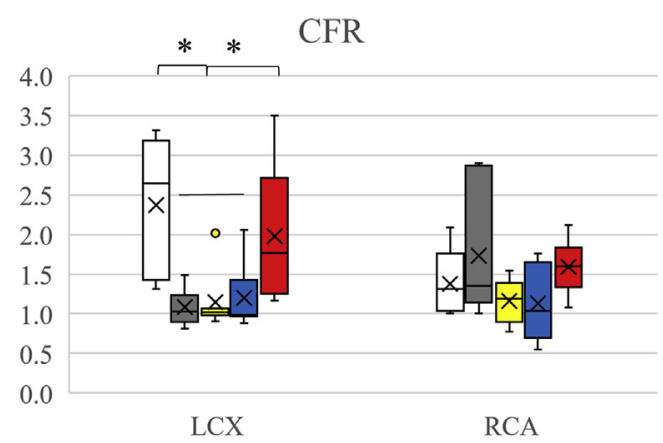

D $\square$ Normal $\square$ Sham $\square$ OM $\square$ ONO $\square$ Combined

FIGURE 1. A, Representative images of collateral arteries in the 4 treatment groups in the left circumflex artery $(L C X)$ and right coronary artery $(R C A)$ territories 4 weeks after treatment. B, Rentrop scores in the LCX and RCA territories 4 weeks after treatment. C, Index of microvascular resistance (IMR) in the LCX and RCA territories 4 weeks after treatment. D, Coronary flow reserve $(C F R)$ in the LCX and RCA territories 4 weeks after treatment. Sham, Saline alone group; $O M$, saline combined with pedicled omental flap group; $O N O$, saline-dissolved ONO-1301SR group; Combined, saline-dissolved ONO1301SR combined with a pedicled omental flap group. $* P<.05$. $* * P<.01$ versus sham or OM group. 

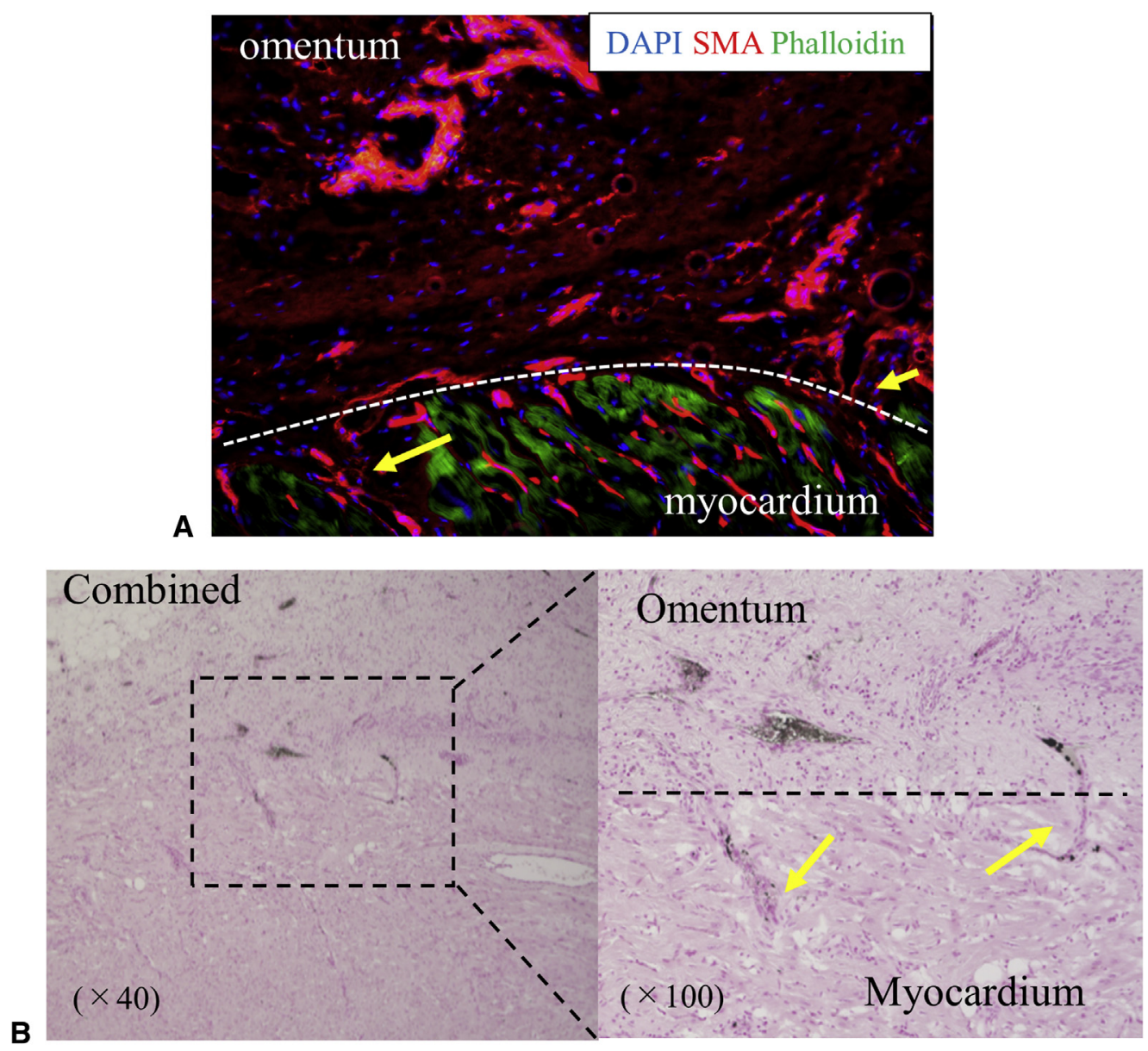

IMR

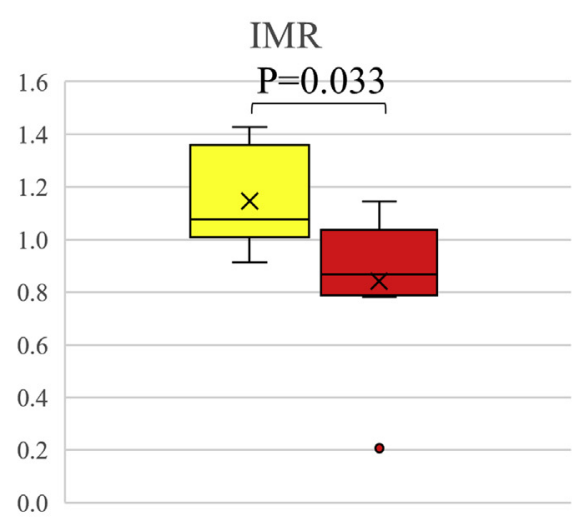

C

$\square \mathrm{OM} \square$ Combined

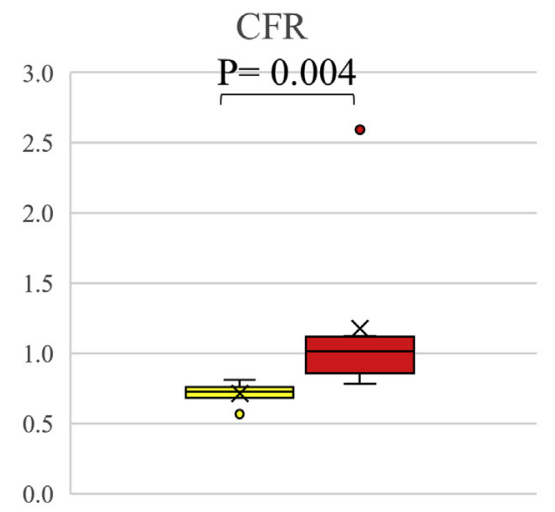

$\square \mathrm{OM} \square$ Combined

FIGURE 2. Vascular connection between the omentum and host myocardium. A, Assessed using immunohistochemical staining. B, Assessed using histologic ink staining (yellow arrow indicates penetrating arteries). C, The change rate in index of microvascular resistance (IMR) and coronary flow reserve $(C F R)$ of the gastroepiploic artery before and after occlusion of left circumflex artery (LCX). DAPI, 4',6-Diamidino-2-phenylindole; SMA, smooth muscle antibody; Combined, saline-dissolved ONO-1301SR combined with a pedicled omental flap group; $O M$, saline combined with pedicled omental flap group.

impaired motion of the corresponding area and global LV dilatation, whereas the combined group subjects seemed to be less affected than the other groups. The combined group displayed a significantly smaller LV endosystolic volume and a tendency for larger LV ejection fraction than the sham and $\mathrm{OM}$ groups, whereas LV endodiastolic volume was not significantly different among the 4 groups (Figure 5, A-E). Notably, recovery of $\mathrm{LV}$ ejection fraction in the combined group was significantly greater than even the ONO group. 


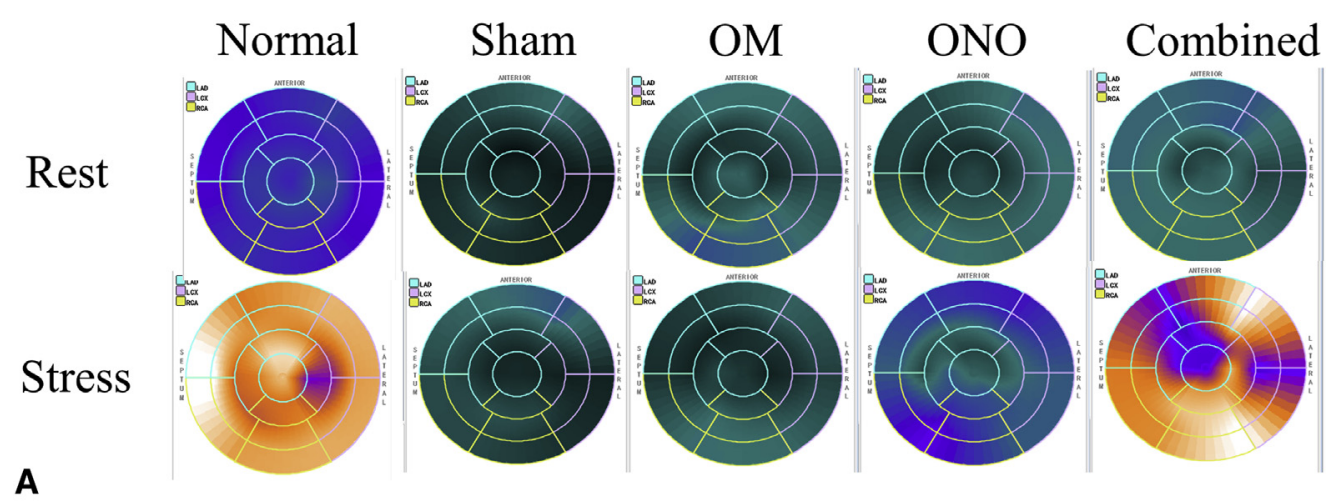

$(\mathrm{ml} / \mathrm{min} . / \mathrm{g})$

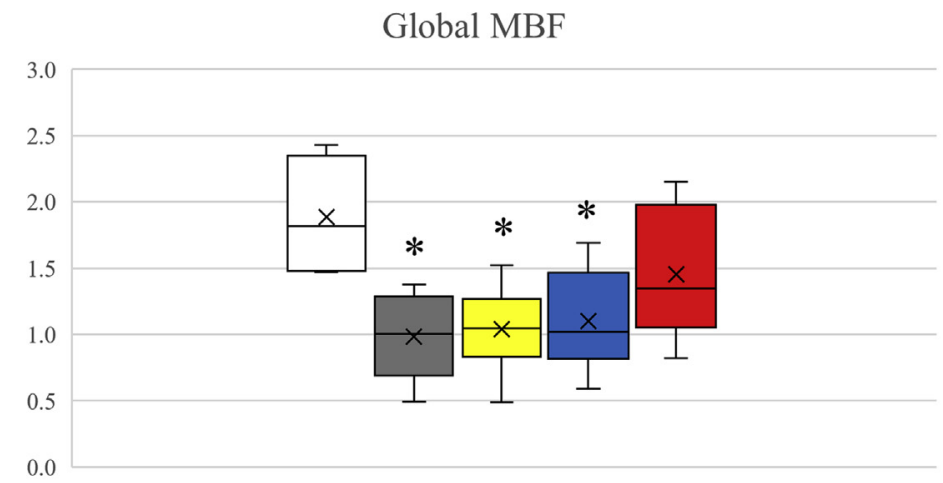

B

$\square$ Normal $\square$ Sham $\square$ OM $\square$ ONO $\square$ Combined
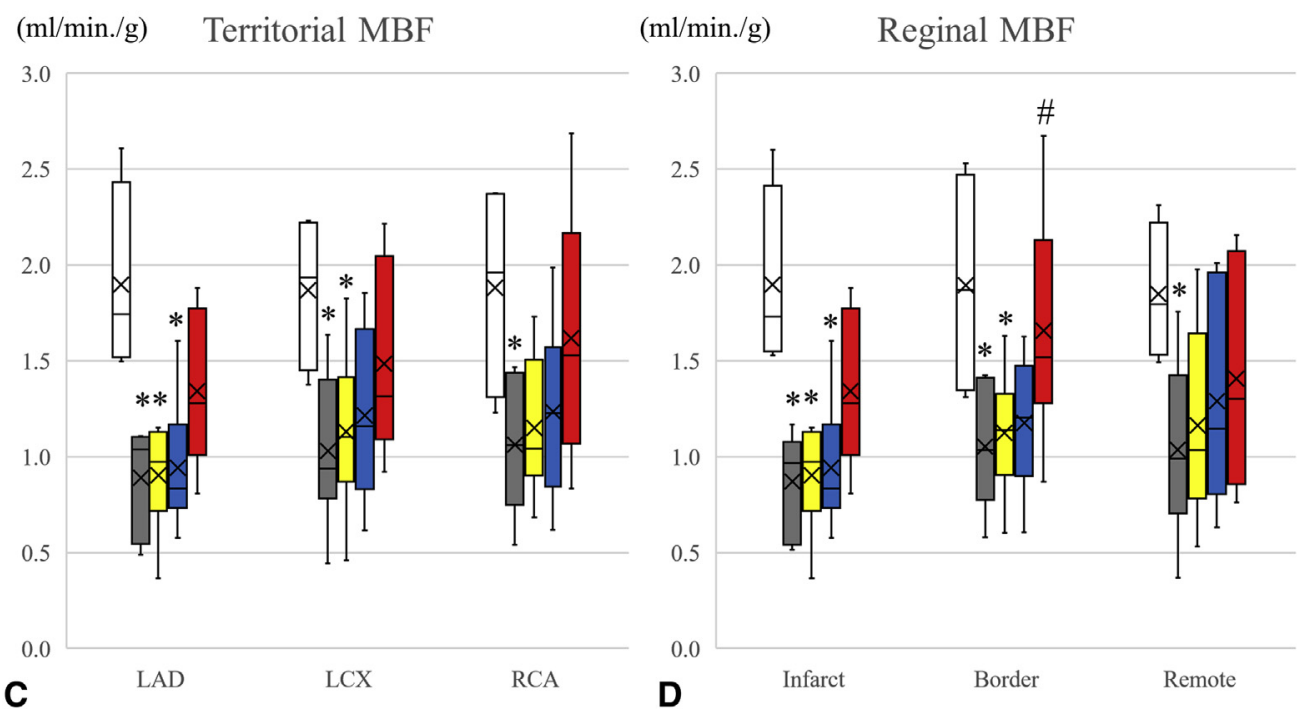

FIGURE 3. A, Representative bull's-eye of myocardial flow reserve $(M B F)$ in the 4 treatment groups and normal left ventricle (LV) 4 weeks after treatment. $\mathrm{B}$, Global. C, Territorial. D, Regional MBF 4 weeks after treatment in the left anterior descending artery $(L A D)$, left circumflex artery $(L C X)$, and right coronary artery $(R C A)$ territories. Sham, Saline alone group; $O M$, saline combined with pedicled omental flap group; $O N O$, saline-dissolved ONO1301SR group; Combined, saline-dissolved ONO-1301SR combined with a pedicled omental flap group. $* P<.05$ versus normal left ventricle. \#P<.05 versus sham group.

Moreover, cardiac MRI dissected the regional systolic function of the LV as circumferential strains (CS) and circumferential strain rates (CSR) of each territory and region (Figure 6, A). As a result, the combined and ONO groups displayed a significantly greater CS of the LAD and LCX territories than the sham group. In contrast, there 


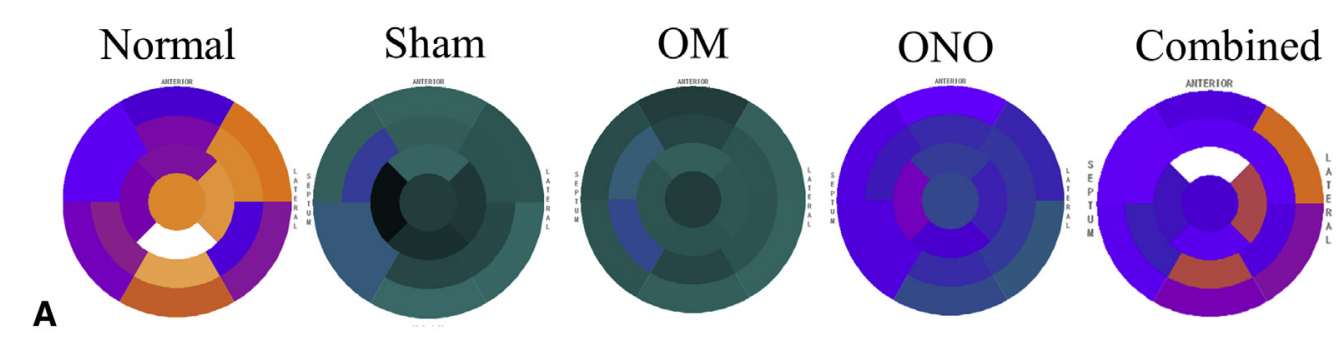

Global MFR

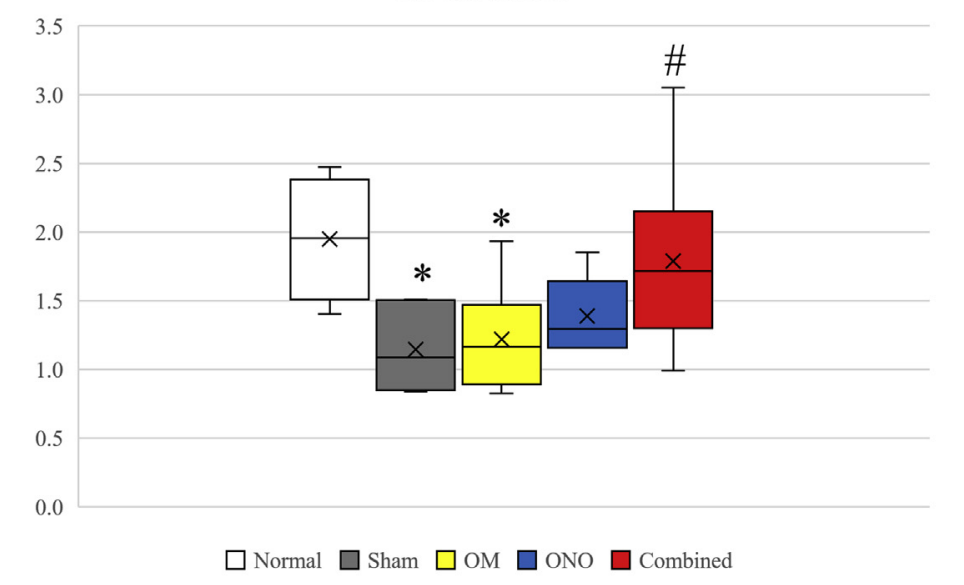

Territorial MFR

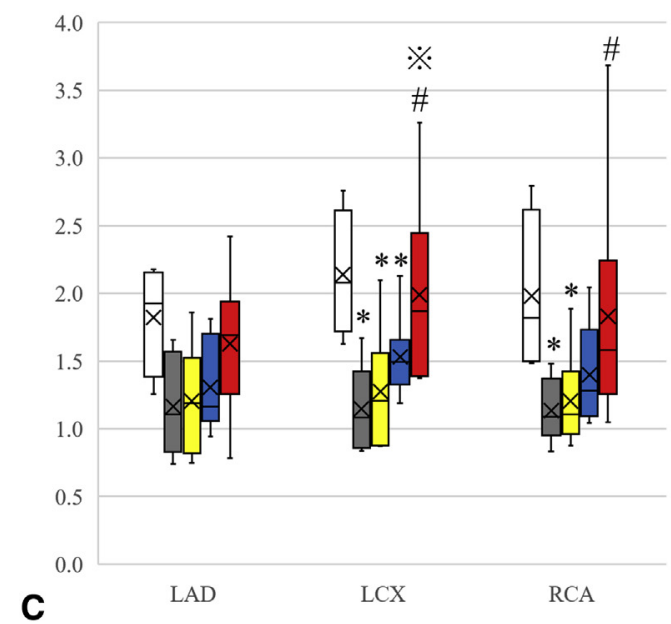

Reginal MFR

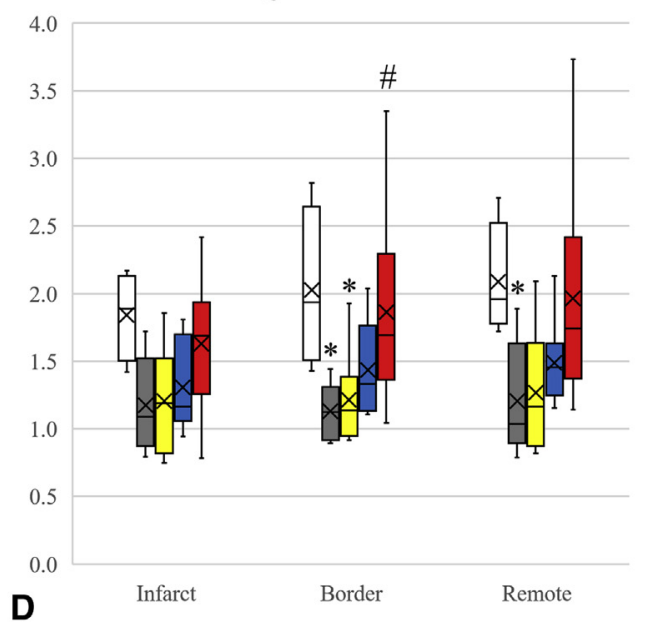

FIGURE 4. A, Representative bull's-eye of myocardial flow reserve $(M F R)$ in the 4 treatment groups and normal left ventricle 4 weeks after the treatment in the left anterior descending artery $(L A D)$, left circumflex artery $(L C X)$, and right coronary artery $(R C A)$ territories. B, Global. C, Territorial. D, Regional. Sham, Saline alone group; $O M$, saline combined with pedicled omental flap group; $O N O$, saline-dissolved ONO-1301SR group; Combined, saline-dissolved ONO-1301SR combined with a pedicled omental flap group. ${ }^{*} P<.05$ versus normal left ventricle. $\# P<.05$ versus sham group. $※ P<.05$ versus OM group.

was no significant difference in the CS of the RCA territory between the 4 treatment groups and the normal LV (Figure 6, B). The combined and ONO groups displayed a significantly greater $\mathrm{CS}$ of the infarct-border region than the sham group. There was no significant difference in the CS of the infarct-remote region between the 4 treatment groups and the normal LV (Figure 6, C). Analysis of the
CSR drew consistent results, such as significantly greater CSR of the infarct-border region in the combined group than the other 3 groups (Figure 5, $D$ and $E$ ).

\section{Histologic and Immunobiologic Analysis}

Pathological LV remodeling was assessed 4 weeks after treatment. The LV structure was better maintained in the 

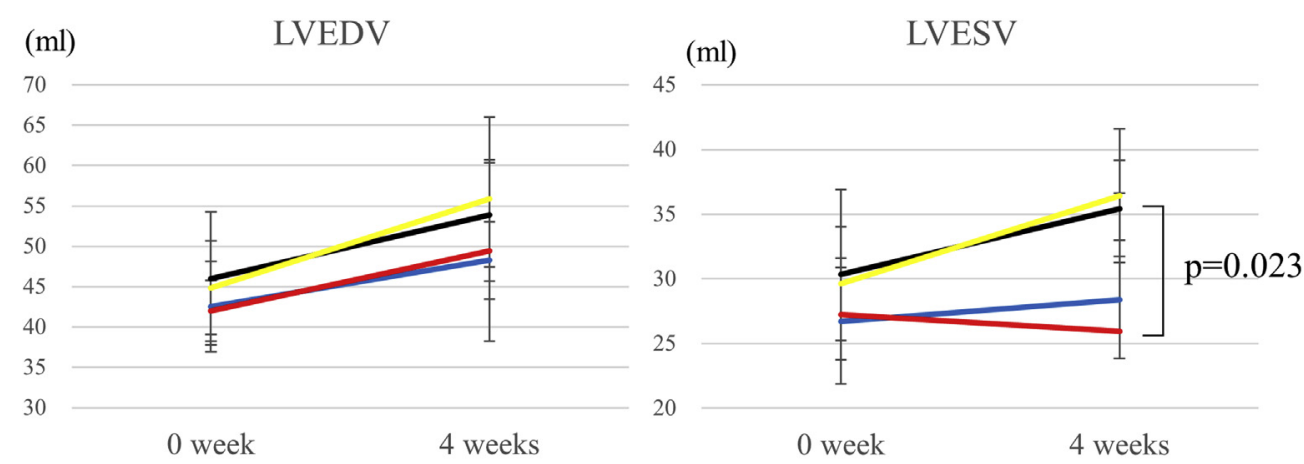

$\mathbf{A}-$ Sham $-\mathrm{OM} \longrightarrow \mathrm{ONO}-$ Combined $\mathbf{B}-\mathrm{Sham}-\mathrm{OM} \longrightarrow \mathrm{ONO}-\mathrm{Combined}$

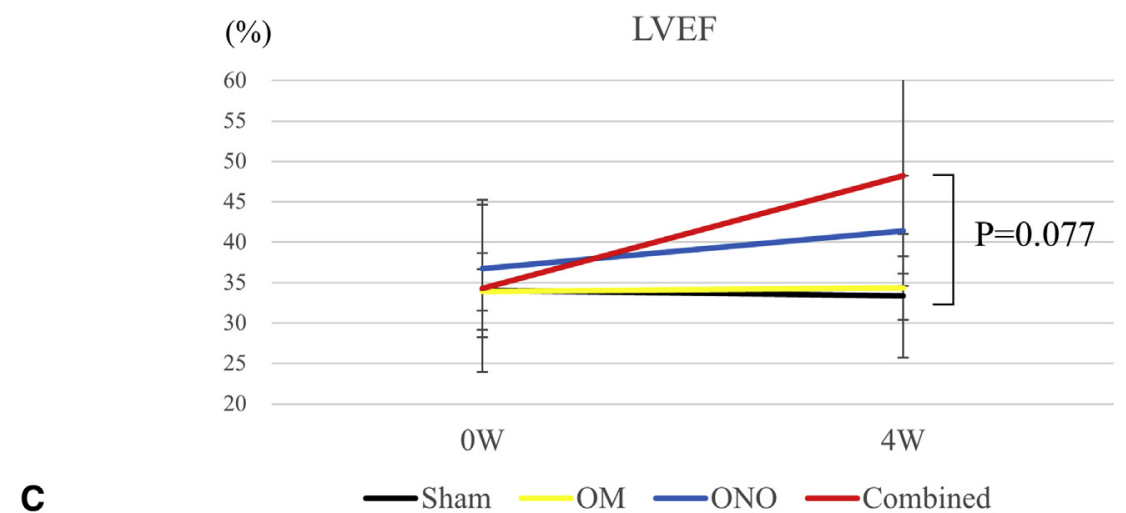

$(\mathrm{ml})$

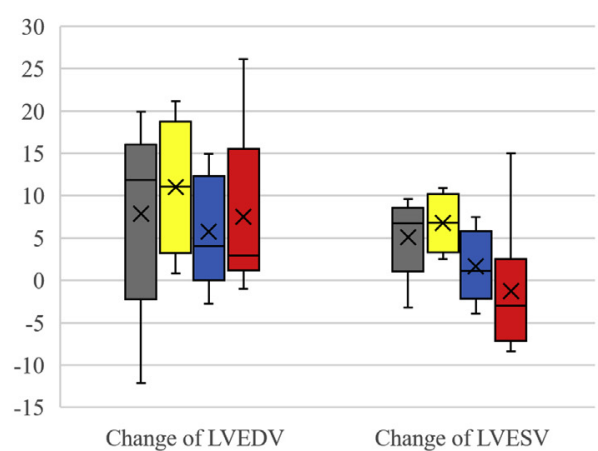

D

$\square$ Sham $\square$ OM $\square$ ONO $\square$ Combined
$(\%)$

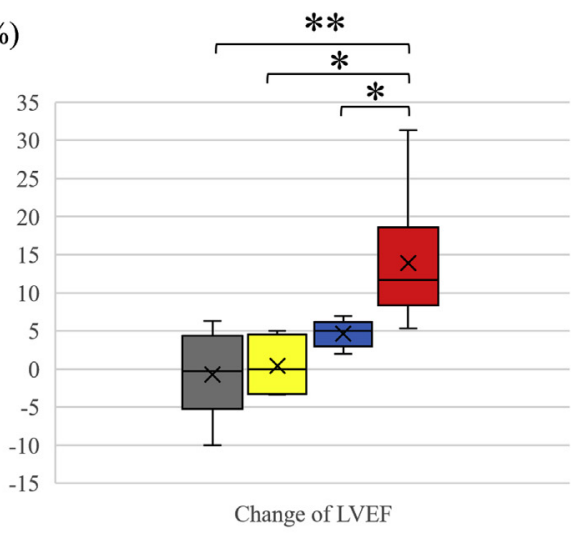

E

$\square$ Sham

$\square \mathrm{OM}$

$\mathrm{ONO}$

Combined

FIGURE 5. Serial changes 0 and 4 weeks after treatment. A, Left ventricular endo-diastolic volume (LVEDV). B, Left ventricular endosystolic volume (LVESV). C, Left ventricular ejection fraction $(L V E F)$. Changes 4 weeks after treatment. D, LVEDV and LVESV. E, LVEF. Sham, Saline alone group; $O M$, saline combined with pedicled omental flap group; $O N O$, saline-dissolved ONO-1301SR group; Combined, saline-dissolved ONO-1301SR combined with a pedicled omental flap group. $* P<.05 ; * * P<.01$.

ONO and combined groups than the other 2 groups, whereas all the subjects showed histologic infarct myocardium in the anteroseptal area (Figure 7, $A$ ). The ONO and combined groups displayed a significantly smaller interstitial fibrosis than the sham group (Figure 7, A). The density of CD31-positive capillaries was significantly greater in the $\mathrm{ONO}$ and combined groups than the other 2 groups, whereas the density of CD31/SMA double-positive arterioles was significantly greater in the combined group compared with the sham and OM groups. In addition, the density of CD31/SMA double-positive capillaries was significantly greater in the combined group than in the ONO group. Similarly, prearterioles $(>100 \mu \mathrm{m})$ were greater in the $\mathrm{ONO}$ and combined groups than in 

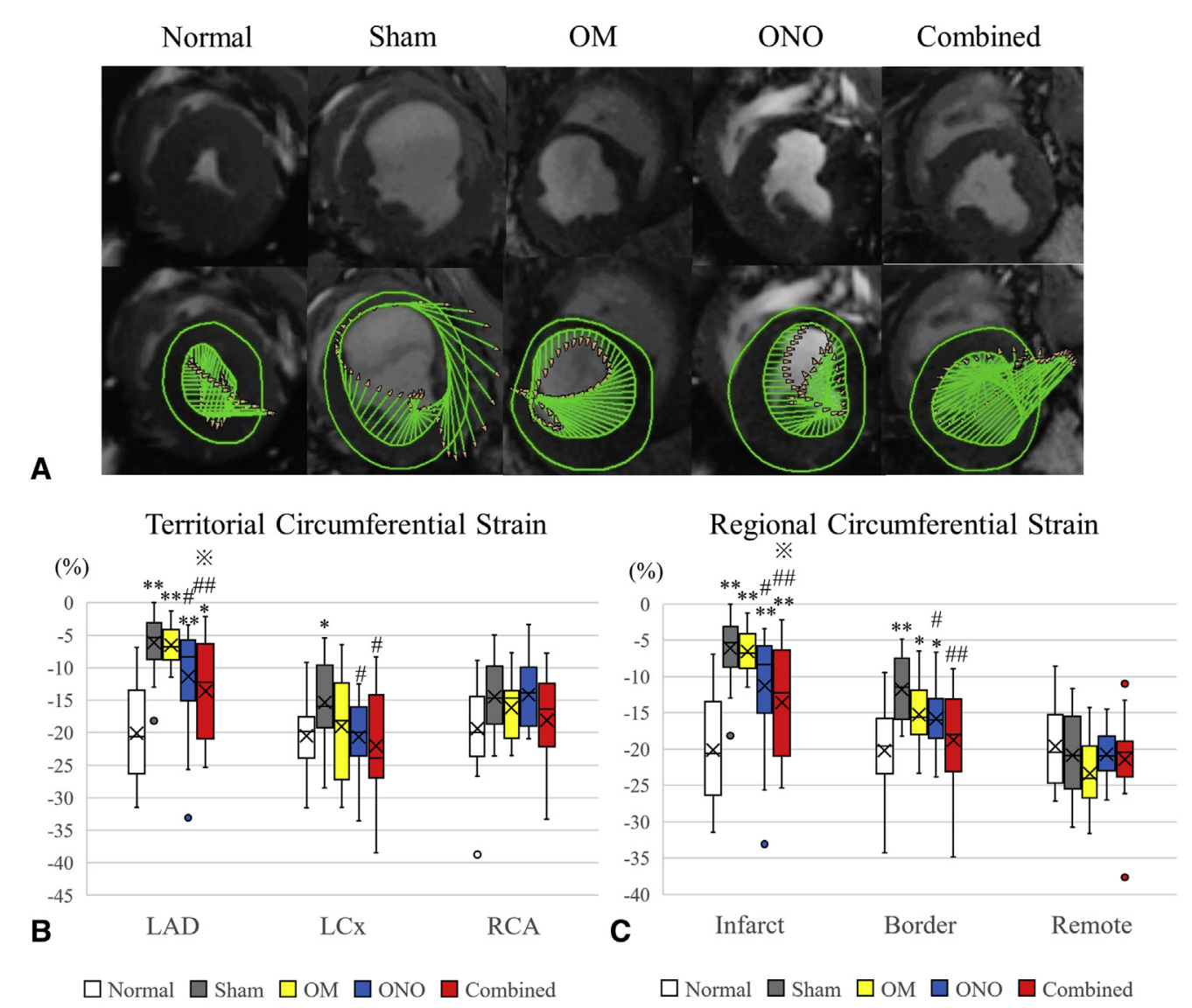

$\left(\mathrm{sec}^{-1}\right)$ Territorial Circumferential Strain Rate

$\left(\mathrm{sec}^{-1}\right)$ Regional Circumferential Strain Rate
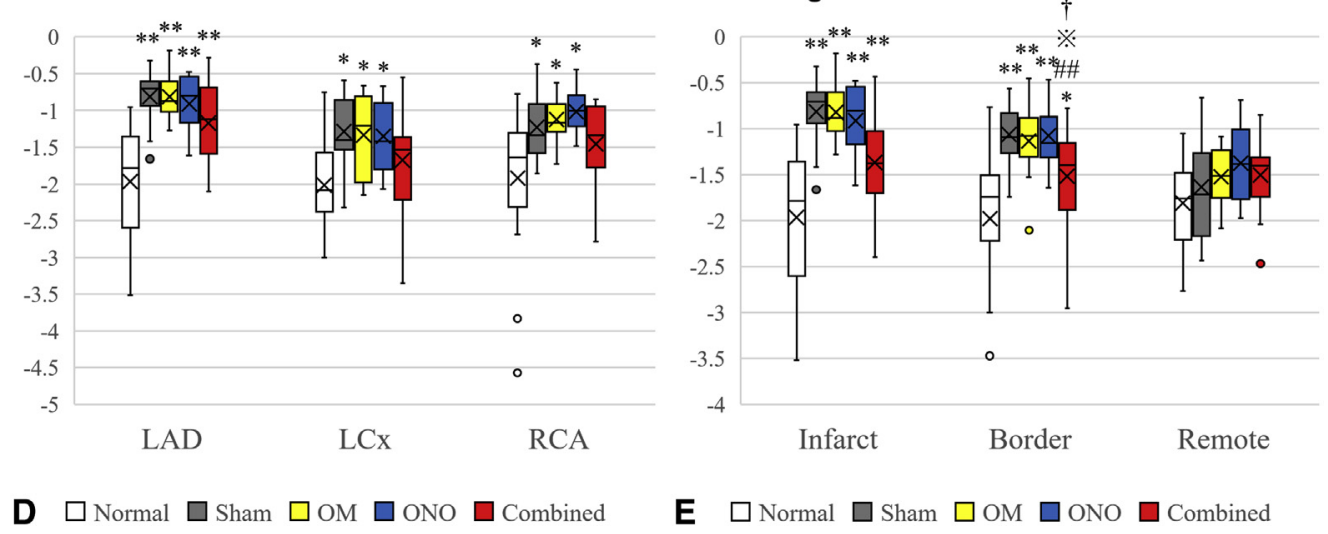

E $\square$ Normal $\square$ Sham $\square$ OM $\square$ ONO $\square$ Combined

FIGURE 6. A, Representative images of endocardial systolic cardiac wall motion at the papillary muscle level 4 weeks after treatment. B, Territorial circumferential strain. C, Regional circumferential strain. D, Territorial circumferential strain rate. E, Regional circumferential strain rate. Sham, Saline alone group; $O M$, saline combined with pedicled omental flap group; $O N O$, saline-dissolved ONO-1301SR group; Combined, saline-dissolved ONO1301SR combined with a pedicled omental flap group; $L A D$, left anterior descending artery; $L C X$, Left circumflex artery; $R C A$, right coronary artery. $* P<.05$. **P $<.01$ versus normal left ventricle. $\# P<.05$. \#\#P<.01 versus sham group. $\circledast P<.05$ versus OM group; $\dagger P<.05$ versus ONO group.

the other 2 groups (Figure 7, B). Myocyte size was significantly smaller in the ONO and combined groups (Figure 7,C).

Moreover, gene expression of proangiogenic cytokines in the infarct-border region 4 weeks after treatment was assessed using real-time polymerase chain reaction for
VEGF, HGF, basic FGF (fibroblast growth factor), and SDF-1. As a result, VEGF and basic FGF expression were significantly greater in the infarct-border region of the ONO and combined groups than in the sham group, whereas expression of HGF or SDF-1 was not significantly different among the 4 groups (Figure $7, D$ ). 

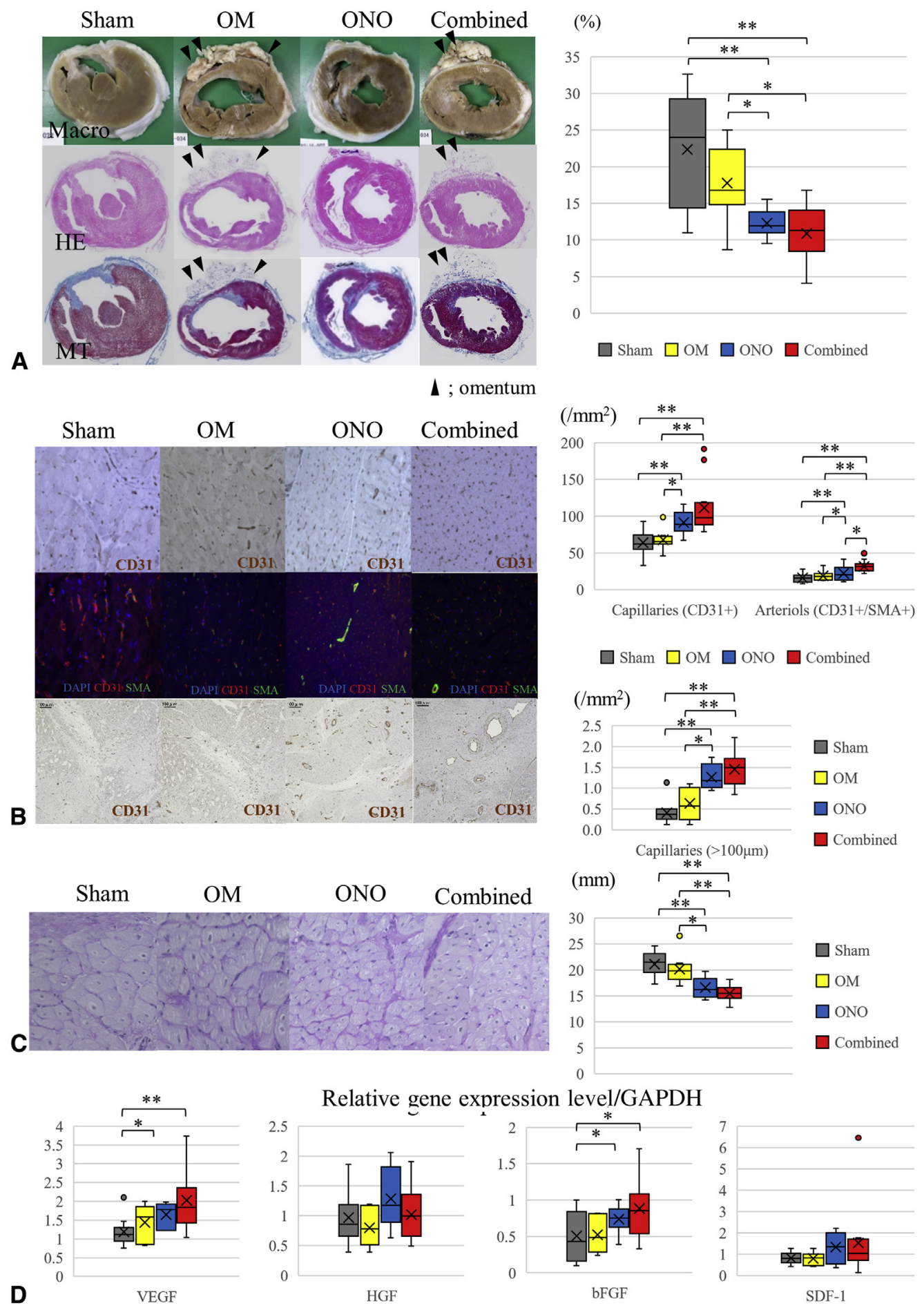

FIGURE 7. A, Myocardial fibrosis 4 weeks after treatment. B, CD31-positive capillaries and CD31/SMA double-positive arterioles in the infarct-border region 4 weeks after treatment. C, Myocyte size 4 weeks after treatment. D, Gene expression of proangiogenic cytokines in the infarct-border region 4 weeks after treatment. Sham, Saline alone group; OM, saline combined with pedicled omental flap group; ONO, saline-dissolved ONO-1301SR group; Combined, saline-dissolved ONO-1301SR combined with a pedicled omental flap group; $H E$, hematoxylin-eosin; $M T$, Masson trichrome; DAPI, 4',6-diamidino-2-phenylindole; $S M A$, smooth muscle antibody; $G A D P H$, glyceraldehyde-3-phosphate dehydrogenase; $V E G F$, vascular endothelial growth factor; $H G F$, hepatocyte growth factor; basic $F G F$, basic fibroblast growth factor; $S D F-1$, stromal cell derived factor 1. $* P<.05$. **P<.01. 


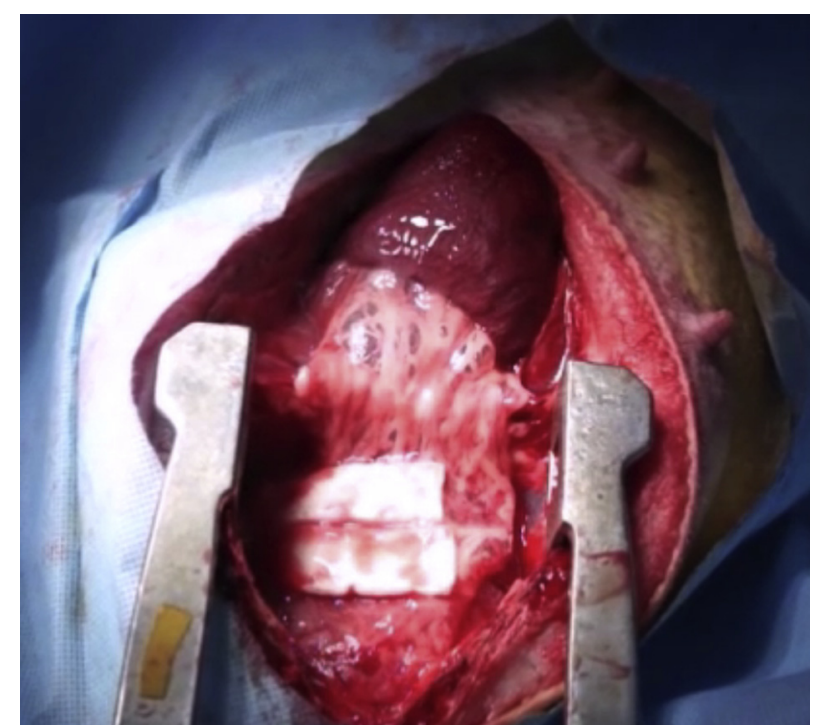

VIDEO 1. The chronic myocardial infarction heart was generated by an ameroid ring around the left anterior descending artery 4 weeks prior and is now viewed through a median sternotomy approach. First, the pedicle omentum is retrieved from the peritoneal space and into the mediastinal space, preserving the arch structure of the gastroepiploic artery to cover the entire left ventricle surface. Subsequently, 2 pieces of ONO1301SR, which is a slow-release prostacyclin agonist, immersed in a gelatin sheet, are placed over the omentum, and finally fibrin glue is applied to fix the gelatin sheet and the omentum on the heart. Video available at: http://www.jtcvsonline.org/article/S0022-5223(18)30713-X/fulltext.

In the infarct-remote region, the combined group showed a greater number of CD31-positive capillaries than the sham group. However, there were no significant differences in gene expression of proangiogenic cytokines among the 4 groups. These results are described in Figure E3.

\section{DISCUSSION}

Herein, we documented the feasibility, safety, and efficacy of combined topical treatment of infarct myocardium with ONO-1301SR and a pedicled omental flap in a porcine ameroid ring-inducing MI model. We also revealed that combined treatment augmented the therapeutic efficacy compared with single treatments such as ONO-1301SR alone or pedicled omentum alone. The combined treatment induced development of collateral arteries in the infarct and infarct-border regions to decrease the resistance of the microvasculature of the corresponding region, as assessed using a selective catheter study. There was a microvascular connection between the myocardium of the infarct-border region and the pedicled omental flap. In addition, there was an increase in regional MBF and MFR in the infarctborder region with combined treatment (assessed with ${ }^{13} \mathrm{~N}$-ammonia PET study). Moreover, global and regional cardiac function was better preserved with combined compared with single treatment, as assessed using cardiac
MRI. Pathological LV remodeling was less prominent with combined treatment than with single treatment.

We previously reported the therapeutic efficacy of ONO1301SR on an MI model via 2 pathways-proangiogenic effects and recruitment of circulating stem/progenitor cells into the infarct-border myocardial tissue. ${ }^{11}$ In this study, the therapeutic effects of ONO-1301SR alone were limited. This inconsistency could be explained by the timing of the treatment. In the previous study, ONO-1301SR was epicardially attached in the acute phase of MI ${ }^{11,15}$ whereas in this study, it was attached 4 weeks after MI induction. In the acute phase of MI, biological and physiological changes sequentially activate multiple pathways, including inflammation or angiogenesis. During this dynamic phase, ONO-1301SR treatment contributed to proangiogenic cytokine-inducing angiogenesis and SDF-1-inducing recruitment of stem/progenitor cells to limit the expansion of infarct tissue. ${ }^{11,15}$ In this study, 4 weeks after MI induction was an appropriate time to converge the acute, dynamic process of MI, whereas the LV remodeling process was prominent in association with progressive impairment of microvascular dysfunction. ONO-1301SR only, which has proangiogenic and anti-inflammatory effects, might have therefore been insufficient to produce statistically significant therapeutic effects on all imaging modalities. Dose optimization would be needed to maximize the therapeutic effects of the ONO-1301SR-only treatment. In contrast, addition of a pedicled omental flap to the ONO-1301SR was shown to augment the therapeutic angiogenesis including the restoration of microvascular function to produce statistically significant therapeutic effects assessed using various imaging modalities and pathologic studies.

Because this study was completed 4 weeks after treatment, the durability of treatment may be questioned. At 4 weeks after treatment, HGF, which is thought to be the major cytokine-related to ONO-1301SR-inducing angiogenesis, and SDF-1, were not upregulated even with combined treatment. Some may speculate that the therapeutic effects of treatment were completed at 4 weeks and that the durability of this treatment would therefore be limited. However, we consider that long-term therapeutic durability would be warranted by the combined treatment for the following reasons. Firstly, settlement of HGF expression at 4 weeks after treatment would indicate that therapeutic angiogenesis, in particular restoration of microvascular dysfunction, was completed at this time. In fact, microvascular resistance, blood flow, and flow reserve in the infarctborder region was normalized with combined treatment at this time. Once a new vascular network was sufficiently developed, regional myocardial ischemia in the infarctborder region, which is the major factor to accelerate the LV remodeling process, would be eliminated, consequently sustaining the functionality of this region as shown in this 
study; however, theoretically, further long-term studies are needed.

VEGF and basic FGF increased 4 weeks after ONO alone and combined treatments, possibly indicating that the myocardium in these 2 groups was still ischemic and needed angiogenesis. However, we consider that angiogenesis is still under way in these 2 groups at this time point to achieve further development of the vascular network in the peri-infarct area. In contrast, in the sham and the OM groups that showed less expression of VEGF or basic FGF, angiogenic activity in the myocardium may have ceased by this time point. Although expression of HGF and SDF-1 was not different among the 4 groups 4 weeks after treatment, these factors might have elevated early and then normalized by 4 weeks in the treatment groups. Because expression of proangiogenic factors is a dynamic event in response to the ischemic insult and any angiogenic treatments, the expression pattern should be variable dependent upon the nature of ischemic insult and treatment. In fact, previous studies have warranted more than 4 weeks of ONO-1301SR treatment, ${ }^{14,15}$ although this work showed 4-week data only. We consider that addition of an omentum flap augments the effect and prolongs durability of ONO1301SR treatment by supplying protective factors from the omentum.

There was no direct significant difference between the ONO and combined groups. However, regional function in the LCX territory and in the peri-infarct area in the combined group was not significantly different from normal LV, although there was a significant difference in regional LV function between the ONO group and the normal LV. In addition, the regional LV function in the ONO group was not significantly different to the sham group. Therefore, therapeutic effects of the combined group were significantly greater than the other groups. In addition, the combined group displayed a beneficial vasodilatation under hyperemic state, showing augmented coronary or myocardial flow reserve to tolerate ischemic insult. Furthermore, we demonstrated the vascular connection between the omentum and the host myocardium, previously reported as "biologic coronary artery bypass grafting." 16,29-31 The bypass offered salvage blood flow in facing cardiac ischemia crisis, confirmed by decreased IMR and increased CFR of the gastroepiploic artery.

In this study, we provided further insight into a chronic MI model. We demonstrated new clinically available modalities that direct epicardial replacement of ONO1301SR with a pedicled omental flap that produced sufficient functional angiogenesis with augmented MBF or MFR, decreased microvascular resistance, and improved regional systolic cardiac function, resulting in ameliorated microvascular dysfunction even in a chronically infarct heart.

There were several limitations. First of all, the sample size was small, possibly resulting in insufficient statistical power. Although some intergroup comparison data might be insignificant due to the type 2 statistical error, the core outcomes and conclusions are still valid. Second, this study may be limited by its relatively short observation period. Given that ONO-1301 is expected to disappear from the body at 4 weeks and previous studies have shown that the effects of ONO-1301SR are still prominent 4 weeks after treatment, ${ }^{11-13}$ we considered that 4 weeks was an optimum point to examine the effects of ONO-1301SR. Third, this preclinical study was limited by the nature of experimental animal use. The minipigs were adolescents with normal coronary arteries apart from the ameroid ring inducing gradual compression of the coronary artery, which is different from the plaque rupture-related MI as seen in human adults. In chronic MI, the microenvironment in the myocardium is damaged by atherosclerotic changes. In contrast, in the porcine model, the microenvironment was maintained to launch the native angiogenic process against the ischemic insult. The angiogenic effects by omentum or ONO-1301SR would be at least in part concealed by this native angiogenic process in the porcine model. We therefore predicted that therapeutic effects of omentum ONO1301SR or a combination of them would be greater in the clinical situation than the healthy porcine model. In fact, all subjects showed complete occlusion of the LAD with development of collateral arteries for the corresponding territory. The next step would therefore be the design of a protocol for clinical investigation of the feasibility and safety of this treatment.

\section{CONCLUSIONS}

ONO-1301SR combined with a pedicled omental flap therapy synergistically promoted myocardial angiogenesis, leading to cardiac functional recovery in a porcine chronic MI model. This cell-free combination therapy shows promise as an effective treatment for enhancement of myocardial angiogenesis in a chronic MI heart.

\section{Conflict of Interest Statement}

Authors have nothing to disclose with regard to commercial support.

The authors thank Nao Mukouyama and Masashi Azuma, Kiwa Laboratory Animals Co Ltd; Yasuo Hara, Masayuki Maniwa, and colleagues, Intervention Technical Center Kobe; and the staff of the PET Molecular Imaging Center, Osaka University Graduate School of Medicine, for their excellent technical assistance.

\section{References}

1. Paulus WJ, Tschope C. A novel paradigm for heart failure with preserved ejection fraction: comorbidities drive myocardial dysfunction and remodeling through coronary microvascular endothelial inflammation. J Am Coll Cardiol. 2013;62:263-71.

2. Camici PG, d'Amati G, Rimoldi O. Coronary microvascular dysfunction: mechanisms and functional assessment. Nat Rev Cardiol. 2015;12:48-62. 
3. Sanganalmath SK, Bolli R. Cell therapy for heart failure: a comprehensive overview of experimental and clinical studies, current challenges, and future directions. Circ Res. 2013;113:810-34.

4. Fedak PW. Paracrine effects of cell transplantation: modifying ventricular remodeling in the failing heart. Semin Thoracic Cardiovasc Surg. 2008;20:87-93.

5. Majed BH, Khalil RA. Molecular mechanisms regulating the vascular prostacyclin pathways and their adaptation during pregnancy and in the newborn. Pharmacol Rev. 2012;64:540-82.

6. Narumiya S, Sugimoto Y, Ushikubi F. Prostanoid receptors: structures, properties, and functions. Physiol Rev. 1999;79:1193-226.

7. Miller SB. Prostaglandins in health and disease: an overview. Semin Arthritis Rheum. 2006;36:37-49.

8. Nakamura K, Sata M, Iwata H, Sakai Y, Hirata Y, Kugiyama K, et al. A synthetic small molecule, ONO-1301, enhances endogenous growth factor expression and augments angiogenesis in the ischaemic heart. Clin Sci (Lond). 2007;112:607-16.

9. Hirata Y, Soeki T, Akaike M, Sakai Y, Igarashi T, Sata M. Synthetic prostacycline agonist, ONO-1301, ameliorates left ventricular dysfunction and cardiac fibrosis in cardiomyopathic hamsters. Biomed Pharmacother. 2009;63:781-6.

10. Hirata Y, Kurobe H, Uematsu E, Yagi S, Soeki T, Yamada H, et al. Beneficial effect of a synthetic prostacyclin agonist, ONO-1301, in rat autoimmune myocarditis model. Eur J Pharmacol. 2013;699:81-7.

11. Imanishi Y, Miyagawa S, Fukushima S, Ishimaru K, Sougawa N, Saito A, et al. Sustained-release delivery of prostacyclin analogue enhances bone marrow-cell recruitment and yields functional benefits for acute myocardial infarction in mice. PLoS ONE. 2013;8:e69302.

12. Ishimaru K, Miyagawa S, Fukushima S, Saito A, Sakai Y, Ueno T, et al. Synthetic prostacyclin agonist, ONO1301, enhances endogenous myocardial repair in a hamster model of dilated cardiomyopathy: a promising regenerative therapy for the failing heart. J Thorac Cardiovasc Surg. 2013;146:1516-25.

13. Shirasaka T, Miyagawa S, Fukushima S, Saito A, Shiozaki M, Kawaguchi N, et al. A slow-releasing form of prostacyclin agonist (ONO1301SR) enhances endogenous secretion of multiple cardiotherapeutic cytokines and improves cardiac function in a rapid-pacing-induced model of canine heart failure. J Thorac Cardiovasc Surg. 2013;146:413-21.

14. Watanabe Y, Miyagawa S, Fukushima S, Daimon T, Shirakawa Y, Kuratani T, et al. Development of a prostacyclin-agonist-eluting aortic stent graft enhancing biological attachment to the aortic wall. J Thorac Cardiovasc Surg. 2014;148: 2325-34.e2321.

15. Kubota Y, Miyagawa S, Fukushima S, Saito A, Watabe H, Daimon T, et al. Impact of cardiac support device combined with slow-release prostacyclin agonist in a canine ischemic cardiomyopathy model. J Thorac Cardiovasc Surg. 2014;147:1081-7.

16. Kainuma S, Miyagawa S, Fukushima S, Pearson J, Chen YC, Saito A, et al. Cellsheet therapy with omentopexy promotes arteriogenesis and improves coronary circulation physiology in failing heart. Mol Ther. 2015;23:374-86.

17. Kawamura M, Miyagawa S, Fukushima S, Saito A, Miki K, Ito E, et al. Enhanced survival of transplanted human induced pluripotent stem cell-derived cardiomyocytes by the combination of cell sheets with the pedicled omental flap technique in a porcine heart. Circulation. 2013;128(Suppl):S87-94.

18. Shudo Y, Miyagawa S, Fukushima S, Saito A, Shimizu T, Okano T, et al. Novel regenerative therapy using cell-sheet covered with omentum flap delivers a huge number of cells in a porcine myocardial infarction model. J Thorac Cardiovasc Surg. 2011;142:1188-96.

19. Miyagawa S, Sawa Y, Sakakida S, Taketani S, Kondoh H, Memon I, et al. Tissue cardiomyoplasty using bioengineered contractile cardiomyocyte sheets to repair damaged myocardium: their integration with recipient myocardium. Transplantation. 2005;80:1586-95.

20. Hata H, Matsumiya G, Miyagawa S, Kondoh H, Kawaguchi N, Matsuura N, et al. Grafted skeletal myoblast sheets attenuate myocardial remodeling in pacing-induced canine heart failure model. J Thorac Cardiovasc Surg. 2006; 132:918-24.

21. Sawa Y, Yoshikawa Y, Toda K, Fukushima S, Yamazaki K, Ono M, et al. Safety and efficacy of autologous skeletal myoblast sheets (TCD-51073) for the treatment of severe chronic heart failure due to ischemic heart disease. Circ $J$. 2015;79:991-9.

22. Shrager JB, Wain JC, Wright CD, Donahue DM, Vlahakes GJ, Moncure AC et al. Omentum is highly effective in the management of complex cardiothoracic surgical problems. J Thorac Cardiovasc Surg. 2003;125:526-32.

23. Levashev YN, Akopov AL, Mosin IV. The possibilities of greater omentum usage in thoracic surgery. Eur J Cardiothorac Surg. 1999;15:465-8.

24. Zhang QX, Magovern CJ, Mack CA, Budenbender KT, Ko W, Rosengart TK Vascular endothelial growth factor is the major angiogenic factor in omentum: mechanism of the omentum-mediated angiogenesis. J Surg Res. 1997;67: 147-54.

25. National Research Council. 2011. Guide for the Care and Use of Laboratory An imals. 8th ed. Washington: The National Academies Press; 2011.

26. Uchida T, Hazekawa M, Morisaki T, Yoshida M, Sakai Y. Effect of antioxidants on the stability of ONO-1301, a novel long-acting prostacyclin agonist, loaded in PLGA microspheres. J Microencapsul. 2013;30:245-56.

27. Uchida T, Hazekawa M, Yoshida M, Matsumoto K, Sakai Y. A novel long-acting prostacyclin agonist (ONO-1301) with an angiogenic effect: promoting synthesis of hepatocyte growth factor and increasing cyclic AMP concentration via IPreceptor signaling. J Pharmacol Sci. 2013;123:392-401.

28. Obata H, Sakai Y, Ohnishi S, Takeshita S, Mori H, Kodama M, et al. Single in jection of a sustained-release prostacyclin analog improves pulmonary hypertension in rats. Am J Respir Crit Care Med. 2008;177:195-201.

29. Kanamori T, Watanabe G, Yasuda T, Nagamine H, Kamiya H, Koshida Y. Hybric surgical angiogenesis: omentopexy can enhance myocardial angiogenesis induced by cell therapy. Ann Thorac Surg. 2006;81:160-7.

30. Takaba K, Jiang C, Nemoto S, Saji Y, Ikeda T, Urayama S, et al. A combination of omental flap and growth factor therapy induces arteriogenesis and increases myocardial perfusion in chronic myocardial ischemia: evolving concept of biologic coronary artery bypass grafting. J Thorac Cardiovasc Surg. 2006;132: 891-9.

31. Ueyama K, Bing G, Tabata Y, Ozeki M, Doi K, Mishimura K, et al. Developmen of biologic coronary artery bypass grafting in a rabbit model: revival of a classic concept with modern biotechnology. J Thorac Cardiovasc Surg. 2004;127: 1608-15.

Key Words: microvascular dysfunction, myocardial blood flow, omental flap, ONO-1301, prostacyclin 


\section{APPENDIX E1. SUPPLEMENTARY METHODS: DEFINITION OF MYOCARDIAL TERRITORY AND REGION}

Cardiac segmental analysis was performed according to the American Heart Association 17-segment model. ${ }^{\text {E1 }}$ The 17 segments were compiled into 3 territories, according to the coronary artery domination, such as the left anterior descending artery (territories 1, 2, 7, 8, 13, and 14), left circumflex artery (LCX) (territories 5, $6,11,12$, and 16), and right coronary artery (RCA) (territories $3,4,9,10$, and 15), and according to the area of the ischemic insult, such as the infarct (territories 1, 2, 7, 8,13 , and 14), border (territories 3, 6, 9, 12, 15, and 16), and remote (territories 4, 5, 10, and 11) areas (Figure E2).

\section{Fluoroscopy-Guided Coronary Angiography and Pressure Wire Study}

Fluoroscopy-guided selective coronary angiography was performed by injection of iopamidol through a catheter (Vista Brite Tip; Cordis, Miami, FL) inserted from the right femoral artery in the supine position under general anesthesia $(n=6$ each). Collateral arteries to the left anterior descending artery territory were graded angiographically in a blinded manner using Rentrop collateral scoring. ${ }^{\text {E2 }}$ Subsequently, a fluoroscopy-guided pressure wire (Radi Medical Systems, Uppsala, Sweden) was inserted to assess the myocardial microvascular resistance in the LCX and RCA territories, according to the reported method by Fearon and colleagues. ${ }^{\mathrm{E} 3}$ Briefly, the coronary pressure wire was calibrated outside the body, equalized to the pressure reading from the guide catheter with the pressure sensor positioned at the ostium of the guide catheter, and then advanced to the distal two-thirds of the LCX and RCA. The index of microvascular resistance was calculated as follows: $3 \mathrm{~mL}$ room-temperature saline was injected into each vessel 3 times at rest, and the resting transit times, which are inversely proportional to the flow, were recorded and averaged. Maximal hyperemia was then achieved using continuous intravenous adenosine at $180 \mathrm{mg} / \mathrm{kg} / \mathrm{min}$ via a central venous catheter. Three milliliters of room-temperature saline was again injected into the culprit vessel, and the hyperemic transit times were recorded and averaged. The mean aortic and distal coronary pressures were recorded during the peak hyperemia.

In the OM and Combined groups, index of microvascular resistance and coronary flow reserve of the gastroepiploic artery at maximal hyperemia were measured before and after occlusion of LCX to assess the function of the collateral arteries from the omentum to the myocardium, followed by injection of liquid ink through the gastroepiploic artery for histologic analysis.

\section{Protocol and Data Analysis of 13N-Ammonia Positron Emission Tomography}

The ${ }^{13} \mathrm{~N}$-ammonia myocardial perfusion positron emission tomography (PET) study was performed with the Headtome-V/SET 2400 W PET System (Shimadzu, Kyoto, Japan) in the left lateral decubitus position on the scanner bed under general anesthesia ( $\mathrm{n}=6$ each). This device provided 47 slices with center-to-center distances of $3.125 \mathrm{~mm}$, whereas the intrinsic spatial resolution was $4.0 \mathrm{~mm}$ in plane and $4.3 \mathrm{~mm}$ full width at half-maximum axially. At rest, ${ }^{13} \mathrm{~N}$-ammonia was injected into an ear vein of all pigs, followed by a $10-\mathrm{mL}$ saline flush. Dynamic imaging was begun at the same time of injection and extended for $10 \mathrm{mi}-$ nutes. Fifteen minutes later, an adenosine stress test was performed at $180 \mu \mathrm{g} / \mathrm{kg} / \mathrm{min}$ for 10 minutes to induce a hyperemic state. Then, at the end of the $5-$ min infusion, ${ }^{13} \mathrm{~N}-$ ammonia was injected and stress dynamic imaging data were acquired for 10 minutes in the 2-dimensional mode. Twenty-five dynamic frames were reconstructed $(6 \times 10$ seconds, $6 \times 20$ seconds, $12 \times 30$ seconds, and $1 \times 60$ seconds, for a total of 10 minutes). Images were reconstructed using a matrix of $128 \times 128$ and filtered back projection. All emission data were corrected for tissue attenuation by means of a transmission scan with an external source of $68 \mathrm{Ge}$ to $68 \mathrm{Ga}$. Heart rate and blood pressure were recorded with continuous electrocardiogram monitoring.

The myocardial blood flow values for ${ }^{13} \mathrm{~N}$-ammonia PET were estimated using the commercially available PMOD software package version 3.4 (PMOD Technologies LLC, Zurich, Switzerland). ${ }^{\mathrm{E} 4}$ The reconstructed images were resliced in the short axis as well as in the vertical and horizontal long-axis orientations. Regions of interest in the left ventricle myocardium were automatically generated and minimally modified as necessary by an experienced reader to best match the cardiac anatomy and avoid contamination from extracardiac activity. Myocardial and blood-pool time-activity curves, generated from the dynamic frames, were fitted with the tracer kinetic model. We adopted the DeGrado 1-compartment model, which assumes that there is no metabolic trapping. ${ }^{\mathrm{E} 4}$ The estimated rest and stress myocardial blood flow were expressed in each segment, territory, and region.

\section{Data Acquisition and Feature-Tracking Analysis With Cardiac Magnetic Resonance Imaging}

A short-axis left ventricle stack from the atrioventricular ring to the left ventricle apex in the cardiac magnetic resonance imaging scal were acquired on a 1.5 Tesla scanner (Signa EXCITE XI TwinSpeed; GE Medical Systems, Milwaukee, Wis) to draw a steady-state free precession images of the basal, midventricular, and apical left ventricle levels of short-axis views. The images were then analyzed using a 
commercial feature tracking software (2D CPA MR; TomTec Imaging Systems, Unterschleissheim, Germany) that is a vector-based analysis tool based on a hierarchical algorithm, which has been validated previously in clinical studies. ${ }^{\text {E5 }}$ For each of the 3 short-axis plane cine images, the left ventricle endocardial border at the end-diastolic frame was manually drawn on a single frame by an expert reader. The software then automatically propagated the contour and followed its features throughout the cardiac cycle to draw the circumferential strain and circumferential strain rate of the 16 segments. The values of the 3 territories stratified by coronary artery domination and by the area of the ischemic insult were compared with those of the normal left ventricle. Left ventricle endodiastolic volume, left ventricle endosystolic volume, and left ventricle ejection fraction were determined by averaging those values, respectively.

\section{Histologic Analysis}

Excised heart samples were fixed with $10 \%$ buffered formalin for paraffin-embedded sections or $4 \%$ paraformaldehyde for frozen sections. Paraffin-embedded sections were stained with hematoxylin-eosin, Masson's trichrome to assess the extent of fibrosis by optical microscopy (Leica, Wetzlar, Germany), and periodic acid-Schiff to measure the short-axis diameter of myocytes. The sections were also labeled immunohistologically by polyclonal anti-CD31 antibody (1:50 CD31; Abcam, Cambridge, United Kingdom) and visualized by the LSABTM kit (Dako, Glostrup, Denmark) and rabbit anti-CD31 antibody (1:50 CD31) and mouse anti-SMA antibody (1:50; Dako, Glostrup, Denmark), and then visualized by the following secondary antibodies: Alexa Fluor 555 goat anti-mouse IgG and Alexa Fluor 488 goat anti-rabbit IgG (Invitrogen, Carlsbad, Calif). The nuclei of the cells were stained with Hoechst 33342 (1:100; Dojindo, Kumamoto, Japan) and then assessed using a confocal laser scanning microscope FV10i (Olympus; Tokyo, Japan). Myocyte diameters and vascular density were measured at the infarct-border area in 5 different randomly selected fields using a Biorevo BZ-9000 fluorescence microscope (Keyence; Osaka,
Japan), and percentage fibrosis was calculated using the MetaMorph software (Molecular Devices; Tokyo, Japan). ${ }^{\text {E6 }}$

\section{Real-Time Polymerase Chain Reaction}

The infarct-border region of the excised heart samples was later immersed in RNA (Invitrogen). Total RNA was isolated from the infarct-border area using the RNeasy Kit (Qiagen, Hilden, Germany) and then reverse-transcribed using Omniscript Reverse Transcriptase (Qiagen). Real-time polymerase chair reaction was performed by using TaqMan Gene Expression Assay Master Mix (Applied Biosystems, Foster City, Calif) on 7500 Fast Real-Time PCR System (Applied Biosystems, Foster City, Calif). The following genes were analyzed using TaqMan Gene Expression Assay (Applied Biosystems): vascular endothelial growth factor (Ss03393993_m1), hepatocyte growth factor (AJVI4PJ), and stromal cell-derived factor (Ss03391855_m1). Glyceraldehyde-3-phosphate dehydrogenase (Ss03374854_g1) was coamplified as an internal control for RNA integrity.

\section{E-References}

E1. Cerqueira MD, Weissman NJ, Dilsizian V, Jacobs AK, Kaul S, Laskey WK, et al. Standardized myocardial segmentation and nomenclature for tomographic imaging of the heart. A statement for healthcare professionals from the Cardiac Imaging Committee of the Council on Clinical Cardiology of the American Heart Association. Circulation. 2002;105:539-42.

E2. Rentrop KP, Cohen M, Blanke H, Phillips RA. Changes in collateral channel filling immediately after controlled coronary artery occlusion by an angioplasty balloon in human subjects. J Am Coll Cardiol. 1985;5:587-92.

E3. Fearon WF, Balsam LB, Farouque HM, Robbins RC, Fitzgerald PJ, Yock PG et al. Novel index for invasively assessing the coronary microcirculation. Circulation. 2003;107:3129-32.

E4. DeGrado TR, Hanson MW, Turkington TG, Delong DM, Brezinski DA, Vallée JP, et al. Estimation of myocardial blood flow for longitudinal studies with 13N-labeled ammonia and positron emission tomography. J Nucl Cardiol. 1996;3:494-507.

E5. Obokata M, Nagata Y, Wu VC, Kado Y, Kurabayashi M, Otsuji Y, et al. Direct comparison of cardiac magnetic resonance feature tracking and 2D/3D echocardiography speckle tracking for evaluation of global left ventricular strain. Eur Heart J Cardiovasc Imaging. 2016;17:525-32.

E6. Kitahara M, Miyagawa S, Fukushima S, Saito A, Shintani A, Akita T, et al Biodegradable vs nonbiodegradable cardiac support device for treating ischemic cardiomyopathy in a canine heart. Semin Thoracic Cardiovasc Surg. 2017;29: $51-61$. 


\section{Ameroid constrictor placement}

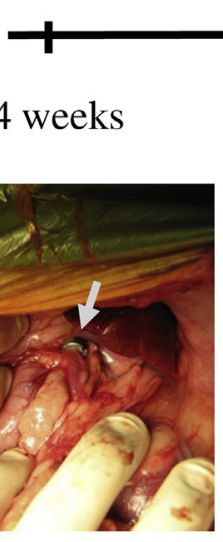

Assignment

$\&$

Examinations
Examinations

$\&$

Sacrifice

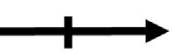

4 weeks

A

- Cardiac MRI

- Cardiac MRI

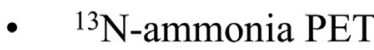

- Pressure wire study

- Histology
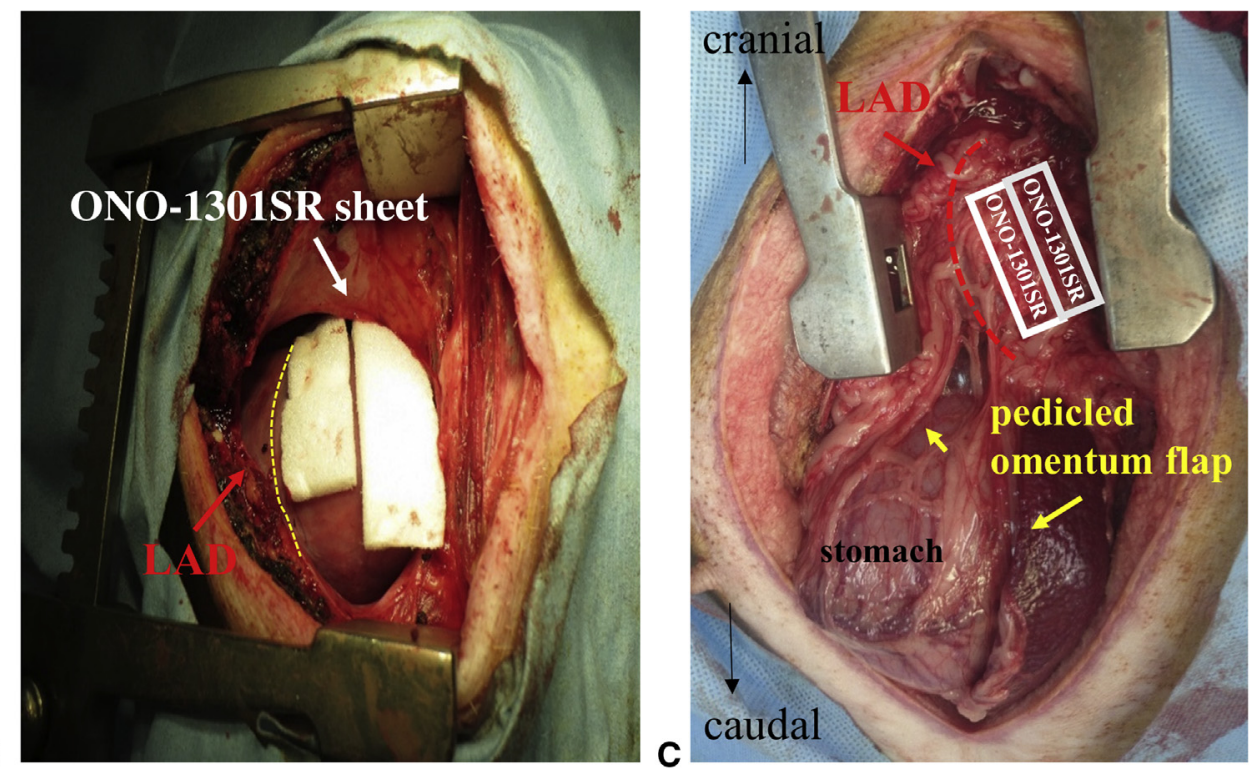

FIGURE E1. A, Experimental protocol. B, Placement of ONO-1301SR-immersed sheet on the left ventricle surface. C, Placement of ONO-1301SRimmersed sheet on the left ventricle surface, followed by covering with a pedicled omental flap. MRI, Magnetic resonance imaging; PET, positron emission tomography. Gray arrow indicates ameroid constrictor ring. 

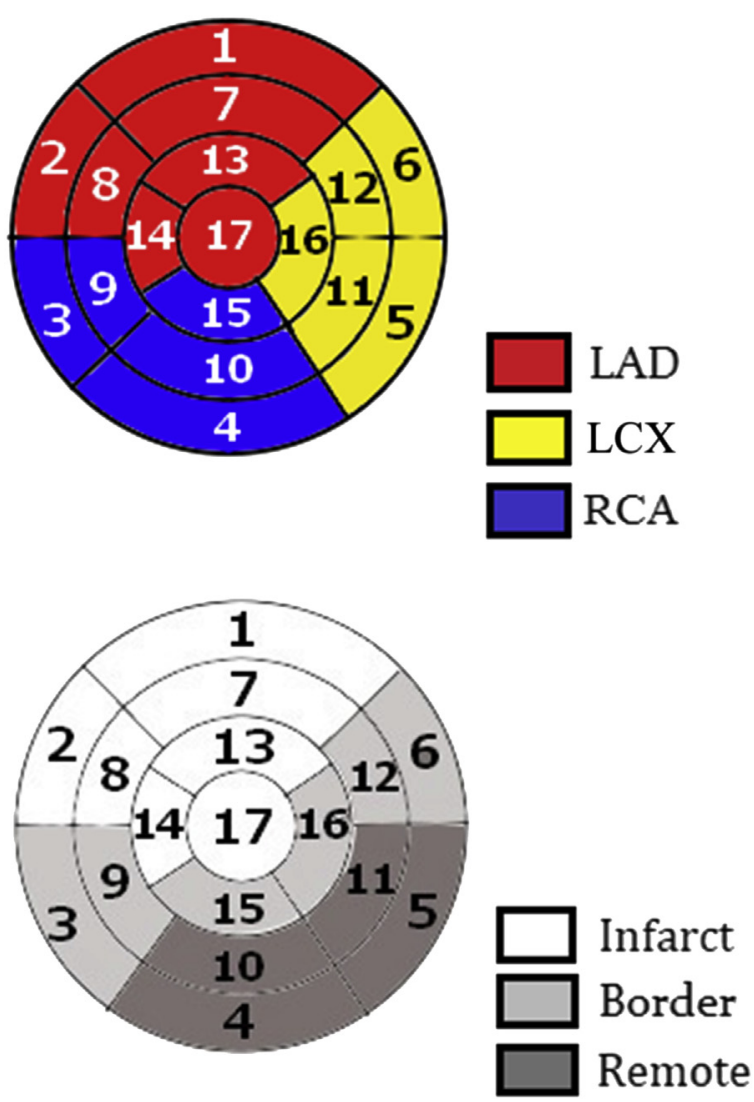

FIGURE E2. Definitions of areas. Upper, Territories stratified by the domination of the coronary arteries. Bottom, Regions stratified by the ischemic insult. $L A D$, Left anterior descending artery; $L C X$, left circumflex artery; $R C A$, right coronary artery. 

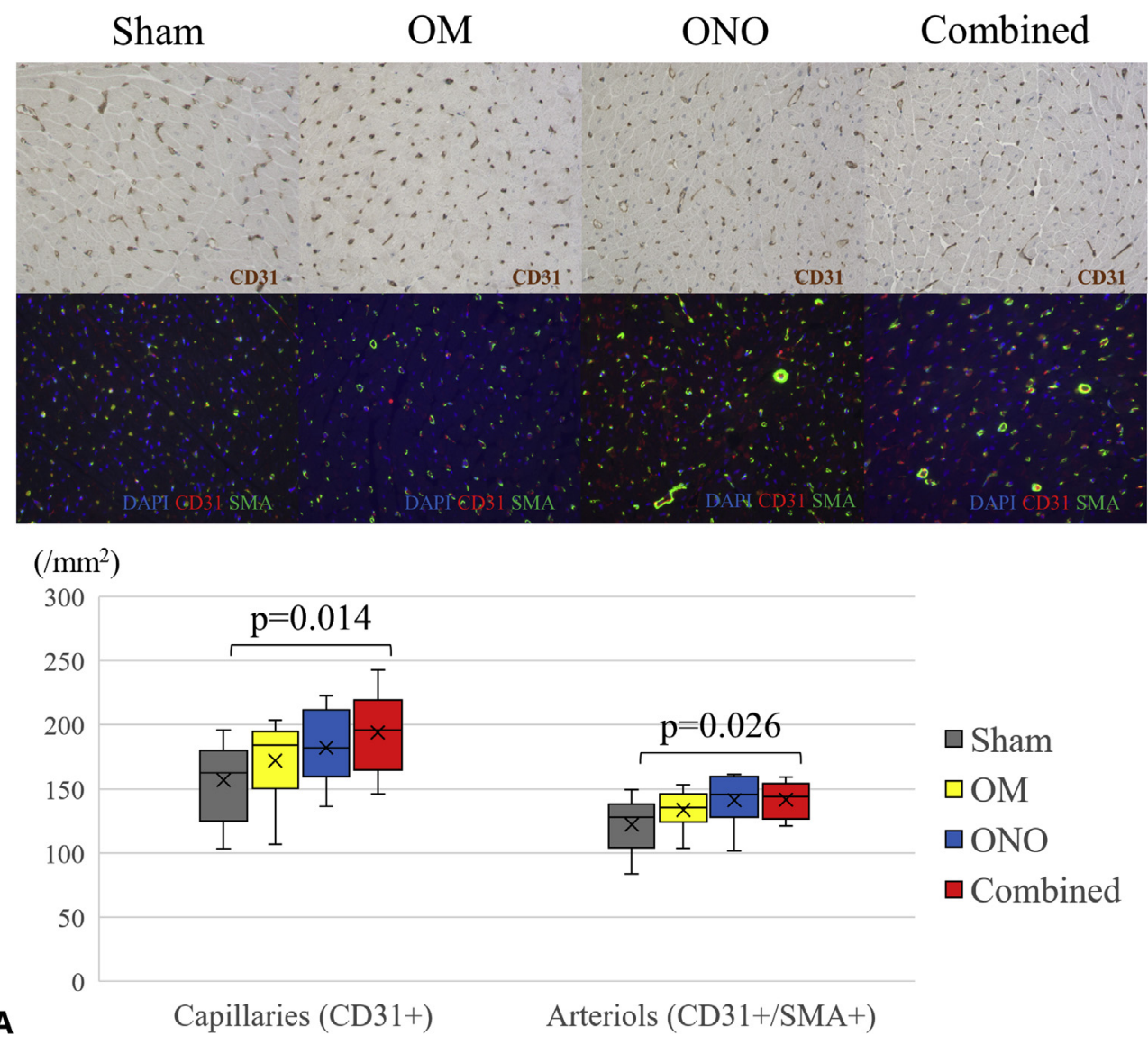

\section{Relative gene expression level/GAPDH}

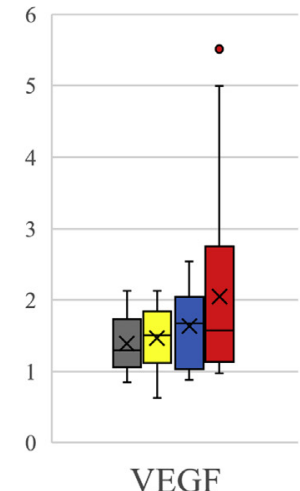

VEGF

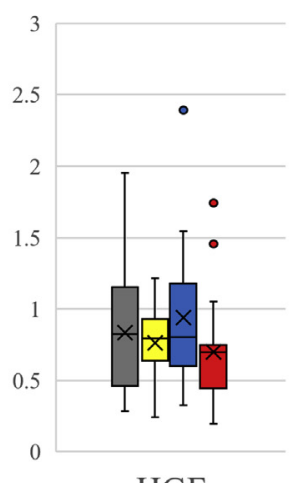

HGF

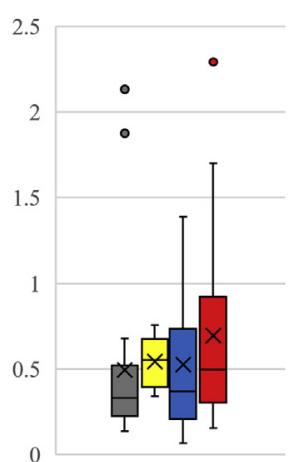

bFGF

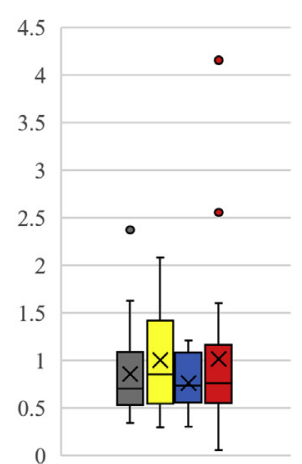

SDF-1

\section{B}

\section{Sham $\square$ OM $\square$ ONO $\square$ Combined}

FIGURE E3. A, CD31-positive capillaries in the infarct-remote region 4 weeks after treatment. B, Gene expression of proangiogenic cytokines in the infarct-remote region 4 weeks after treatment. OM, Saline combined with pedicled omental flap group; ONO, saline-dissolved ONO-1301SR group; Combined, saline-dissolved ONO-1301SR combined with a pedicled omental flap group; DAPI, 4',6-diamidino-2-phenylindole; SMA, smooth muscle antibody; $G A D P H$, glyceraldehyde-3-phosphate dehydrogenase; $V E G F$, vascular endothelial growth factor; $H G F$, hepatocyte growth factor; $b F G F$, basic fibroblast growth factor; $S D F-1$, stromal cell derived factor 1. 
TABLE E1. Details of Figure 1

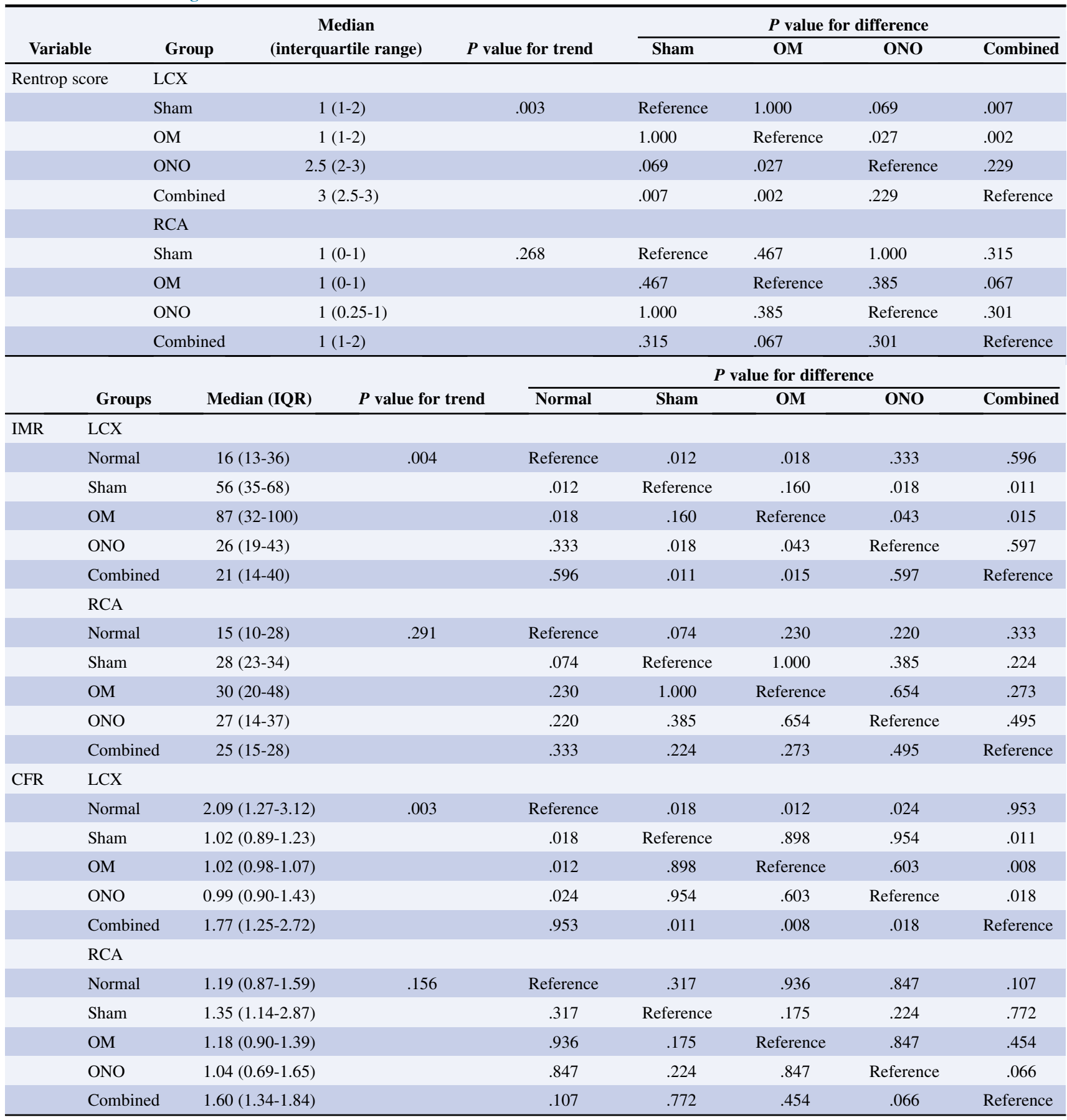

All $P$ values for trend were estimated by Kruskal-Wallis analysis, and $P$ for difference were estimated by Mann-Whitney $U$ test. Sham, Saline alone group; $O M$, saline combined with pedicled omental flap group; $O N O$, saline-dissolved ONO-1301SR group; Combined, saline-dissolved ONO-1301SR combined with a pedicled omental flap group; $L C X$, left circumflex artery; $R C A$, right coronary artery; IMR, index of microvascular resistance; $C F R$, coronary flow reserve.

TABLE E2. The details of Figure 2

\begin{tabular}{lccc}
\hline & OM & Combined & $P$ value \\
\hline IMR & $1.08(1.01-1.36)$ & $0.87(0.79-1.04)$ & .033 \\
CFR & $0.73(0.68-0.76)$ & $1.02(0.86-1.12)$ & .004 \\
\hline
\end{tabular}

Values are presented as median (interquartile range). OM, Saline combined with pedicled omental flap group; Combined, saline-dissolved ONO-1301SR combined with a pedicled omental flap group; IMR, index of microvascular resistance, $C F R$, coronary flow reserve. 
TABLE E3. Details of Figure 3

\begin{tabular}{|c|c|c|c|c|c|c|c|c|}
\hline \multirow[b]{2}{*}{ Variable } & \multirow[b]{2}{*}{ Groups } & \multirow{2}{*}{$\begin{array}{c}\text { Median } \\
\text { (interquartile range) }\end{array}$} & \multirow[b]{2}{*}{$P$ value for trend } & \multicolumn{5}{|c|}{$P$ value for difference } \\
\hline & & & & Normal & Sham & OM & ONO & Combined \\
\hline \multirow[t]{5}{*}{ Global MBF (mL/min/g) } & Normal & $1.82(1.48-2.35)$ & .046 & Reference & .014 & .043 & .043 & .166 \\
\hline & Sham & $1.01(0.69-1.29)$ & & .014 & Reference & .936 & .689 & .093 \\
\hline & $\mathrm{OM}$ & $1.05(0.83-1.27)$ & & .043 & .936 & Reference & 1.000 & .174 \\
\hline & ONO & $1.02(0.82-1.46)$ & & .043 & .689 & 1.000 & Reference & .298 \\
\hline & Combined & $1.35(1.05-1.98)$ & & .166 & .093 & .174 & .298 & Reference \\
\hline \multirow[t]{18}{*}{ Territorial MBF (mL/min/g) } & LAD & & & & & & & \\
\hline & Normal & $1.74(1.52-2.43)$ & .015 & Reference & .014 & .014 & .043 & .110 \\
\hline & Sham & $1.04(0.54-1.10)$ & & .014 & Reference & 1.000 & .810 & .066 \\
\hline & $\mathrm{OM}$ & $0.97(0.72-1.13)$ & & .014 & 1.000 & Reference & .689 & .093 \\
\hline & ONO & $0.83(0.73-1.17)$ & & .043 & .810 & .689 & Reference & .066 \\
\hline & Combined & $1.28(1.01-1.77)$ & & .110 & .066 & .093 & .066 & Reference \\
\hline & LCX & & & & & & & \\
\hline & Normal & $1.94(1.45-2.22)$ & .072 & Reference & .025 & .043 & .070 & .166 \\
\hline & Sham & $0.94(0.78-1.40)$ & & .025 & Reference & .471 & .471 & .174 \\
\hline & $\mathrm{OM}$ & $1.10(0.87-1.42)$ & & .043 & .471 & Reference & .936 & .230 \\
\hline & ONO & $1.16(0.83-1.67)$ & & .070 & .471 & .936 & Reference & .379 \\
\hline & Combined & $1.31(1.09-2.05)$ & & .166 & .174 & .230 & .379 & Reference \\
\hline & RCA & & & & & & & \\
\hline & Normal & $1.96(1.31-2.37)$ & .135 & Reference & .043 & .936 & .575 & .594 \\
\hline & Sham & $1.06(0.75-1.44)$ & & .043 & Reference & .936 & .575 & .128 \\
\hline & $\mathrm{OM}$ & $1.04(0.90-1.51)$ & & .936 & .936 & Reference & .936 & .230 \\
\hline & ONO & $1.23(0.84-1.57)$ & & .575 & .575 & .936 & Reference & .298 \\
\hline & Combined & $1.53(1.07-2.17)$ & & .594 & .128 & .230 & .298 & Reference \\
\hline \multirow[t]{18}{*}{ Regional MBF (mL/min/g) } & Infarct & & & & & & & \\
\hline & Normal & $1.74(1.52-2.43)$ & .015 & Reference & .014 & .014 & .043 & .110 \\
\hline & Sham & $1.04(0.54-1.10)$ & & .014 & Reference & 1.000 & .810 & .066 \\
\hline & $\mathrm{OM}$ & $0.97(0.72-1.13)$ & & .014 & 1.000 & Reference & .689 & .093 \\
\hline & ONO & $0.83(0.73-1.17)$ & & .043 & .810 & .689 & Reference & .066 \\
\hline & Combined & $1.28(1.01-1.77)$ & & .110 & .066 & .093 & .066 & Reference \\
\hline & Border & & & & & & & \\
\hline & Normal & $1.87(1.35-2.47)$ & .025 & Reference & .043 & .043 & .070 & .749 \\
\hline & Sham & $1.03(0.77-1.41)$ & & .043 & Reference & .575 & .471 & .045 \\
\hline & $\mathrm{OM}$ & $1.14(0.90-1.33)$ & & .043 & .575 & Reference & .936 & .128 \\
\hline & ONO & $1.20(0.90-1.47)$ & & .070 & .471 & .936 & Reference & .174 \\
\hline & Combined & $1.52(1.28-2.13)$ & & .749 & .045 & .128 & .174 & Reference \\
\hline & Remote & & & & & & & \\
\hline & Normal & $1.79(1.53-2.22)$ & .261 & Reference & .043 & .110 & .166 & .241 \\
\hline & Sham & $0.99(0.70-1.42)$ & & .043 & Reference & .689 & .575 & .471 \\
\hline & $\mathrm{OM}$ & $1.04(0.78-1.64)$ & & .110 & .689 & Reference & 1.000 & .471 \\
\hline & ONO & $1.15(0.81-1.96)$ & & .166 & .575 & 1.000 & Reference & .575 \\
\hline & Combined & $1.30(0.86-2.07)$ & & .241 & .471 & .471 & .575 & Reference \\
\hline
\end{tabular}

All $P$ values for trend were estimated by Kruskal-Wallis analysis, and $P$ values for difference were estimated by Mann-Whitney $U$ test. Sham, Saline alone group; $O M$, saline combined with pedicled omental flap group; $O N O$, saline-dissolved ONO-1301SR group; Combined, saline-dissolved ONO-1301SR combined with a pedicled omental flap group; $M B F$, myocardial blood flow; $L A D$, left anterior descending artery; $L C X$, left circumflex artery; $R C A$, right coronary artery. 
TABLE E4. Details of Figure 4

\begin{tabular}{|c|c|c|c|c|c|c|c|c|}
\hline \multirow[b]{2}{*}{ Variable } & \multirow[b]{2}{*}{ Groups } & \multirow{2}{*}{$\begin{array}{c}\text { Median } \\
\text { (interquartile range) }\end{array}$} & \multirow[b]{2}{*}{$P$ value for trend } & \multicolumn{5}{|c|}{$P$ value for difference } \\
\hline & & & & Normal & Sham & $\mathbf{O M}$ & ONO & Combined \\
\hline \multirow[t]{5}{*}{ Global MFR } & Normal & $1.96(1.51-2.38)$ & .045 & Reference & .043 & .043 & .070 & .594 \\
\hline & Sham & $1.09(0.85-1.50)$ & & .043 & Reference & 1.000 & .230 & .045 \\
\hline & $\mathrm{OM}$ & $1.16(0.89-1.47)$ & & .043 & 1.000 & Reference & .298 & .128 \\
\hline & ONO & $1.29(1.16-1.64)$ & & .070 & .230 & .298 & Reference & .298 \\
\hline & Combined & $1.71(1.30-2.15)$ & & .594 & .045 & .128 & .298 & Reference \\
\hline \multirow[t]{18}{*}{ Territorial MFR } & LAD & & & & & & & \\
\hline & Normal & $1.93(1.38-2.15)$ & .139 & Reference & .070 & .110 & .070 & .594 \\
\hline & Sham & $1.11(0.83-1.57)$ & & .070 & Reference & .936 & .379 & .128 \\
\hline & $\mathrm{OM}$ & $1.19(0.82-1.52)$ & & .110 & .936 & Reference & .689 & .174 \\
\hline & ONO & $1.16(1.06-1.70)$ & & .070 & .379 & .689 & Reference & .379 \\
\hline & Combined & $1.69(1.26-1.94)$ & & .594 & .128 & .174 & .379 & Reference \\
\hline & LCX & & & & & & & \\
\hline & Normal & $2.08(1.72-2.61)$ & .008 & Reference & .025 & .043 & .043 & .749 \\
\hline & Sham & $1.08(0.86-1.42)$ & & .025 & Reference & .471 & .066 & .013 \\
\hline & $\mathrm{OM}$ & $1.21(0.88-1.56)$ & & .043 & .471 & Reference & .128 & .045 \\
\hline & ONO & $1.50(1.32-1.66)$ & & .043 & .066 & .128 & Reference & .230 \\
\hline & Combined & $1.87(1.39-2.45)$ & & .749 & .013 & .045 & .230 & Reference \\
\hline & RCA & & & & & & & \\
\hline & Normal & $1.82(1.50-1.82)$ & .034 & Reference & .014 & .043 & .110 & .594 \\
\hline & Sham & $1.09(0.95-1.37)$ & & .014 & Reference & 1.000 & .230 & .045 \\
\hline & $\mathrm{OM}$ & $1.11(0.96-1.42)$ & & .043 & 1.000 & Reference & .298 & .093 \\
\hline & ONO & $1.28(1.09-1.73)$ & & .110 & .230 & .298 & Reference & .379 \\
\hline & Combined & $1.58(1.26-2.24)$ & & .594 & .045 & .093 & .379 & Reference \\
\hline \multirow[t]{18}{*}{ Regional MFR } & Infarct & & & & & & & \\
\hline & Normal & $1.93(1.38-2.15)$ & .139 & Reference & .070 & .110 & .070 & .594 \\
\hline & Sham & $1.11(0.83-1.57)$ & & .070 & Reference & .936 & .379 & .128 \\
\hline & $\mathrm{OM}$ & $1.19(0.82-1.52)$ & & .110 & .936 & Reference & .689 & .174 \\
\hline & ONO & $1.16(1.06-1.70)$ & & .070 & .379 & .689 & Reference & .379 \\
\hline & Combined & 1.69 (1.26-1.94) & & .594 & .128 & .174 & .379 & Reference \\
\hline & Border & & & & & & & \\
\hline & Normal & $1.93(1.51-2.64)$ & .028 & Reference & .025 & .043 & .110 & .749 \\
\hline & Sham & $1.13(0.92-1.31)$ & & .025 & Reference & 1.000 & .174 & .020 \\
\hline & $\mathrm{OM}$ & $1.14(0.95-1.38)$ & & .043 & 1.000 & Reference & .230 & .093 \\
\hline & ONO & $1.33(1.13-1.76)$ & & .110 & .174 & .230 & Reference & .379 \\
\hline & Combined & $1.69(1.36-2.29)$ & & .749 & .020 & .093 & .379 & Reference \\
\hline & Remote & & & & & & & \\
\hline & Normal & $1.96(1.78-2.53)$ & .051 & Reference & .025 & .070 & .070 & .456 \\
\hline & Sham & $1.04(0.89-1.63)$ & & .025 & Reference & .810 & .230 & .066 \\
\hline & $\mathrm{OM}$ & $1.16(0.87-1.64)$ & & .070 & .810 & Reference & .298 & .128 \\
\hline & ONO & $1.45(1.25-1.63)$ & & .070 & .230 & .298 & Reference & .471 \\
\hline & Combined & $1.74(1.37-2.42)$ & & .456 & .066 & .128 & .471 & Reference \\
\hline
\end{tabular}

All $P$ values for trend were estimated by Kruskal-Wallis analysis, and $P$ for difference were estimated by Mann-Whitney $U$ test. Sham, Saline alone group; $O M$, saline combined with pedicled omental flap group; $O N O$, saline-dissolved ONO-1301SR group; Combined, saline-dissolved ONO-1301SR combined with a pedicled omental flap group; MFR, myocardial flow reserve; $L A D$, left anterior descending artery, $L C X$, left circumflex artery; $R C A$, right coronary artery. 
TABLE E5. Details of Figure 5

\begin{tabular}{|c|c|c|c|c|c|c|c|}
\hline \multirow[b]{2}{*}{ Variable } & \multirow[b]{2}{*}{ Group } & \multirow{2}{*}{$\begin{array}{c}\text { Median } \\
\text { (interquartile range) }\end{array}$} & \multirow[b]{2}{*}{$P$ value for trend } & \multicolumn{4}{|c|}{$P$ value for difference } \\
\hline & & & & Sham & OM & ONO & Combined \\
\hline \multirow[t]{15}{*}{ LVEDV (mi) } & $0 \mathrm{wk}$ & & & & & & \\
\hline & Sham & $43.6(40.1-52.9)$ & .937 & Reference & 1.000 & .648 & .689 \\
\hline & $\mathrm{OM}$ & $42.3(41.6-50.8)$ & & 1.000 & Reference & .903 & .749 \\
\hline & ONO & $44.1(36.7-47.7)$ & & .648 & .903 & Reference & .927 \\
\hline & Combined & $42.7(37.7-45.3)$ & & .689 & .749 & .927 & Reference \\
\hline & $4 \mathrm{wk}$ & & & & & & \\
\hline & Sham & $53.7(47.9-58.2)$ & .370 & Reference & .749 & .235 & .223 \\
\hline & $\mathrm{OM}$ & $57.8(45.3-64.5)$ & & .749 & Reference & .178 & .456 \\
\hline & ONO & $49.3(43.5-52.5)$ & & .235 & .178 & Reference & .784 \\
\hline & Combined & $46.7(40.4-57.8)$ & & .223 & .456 & .784 & Reference \\
\hline & Change of $\mathrm{I}$ & DV & & & & & \\
\hline & Sham & $11.8(-2.3-16.1)$ & .871 & Reference & .915 & .648 & .810 \\
\hline & $\mathrm{OM}$ & $11.0(3.2-18.7)$ & & .915 & Reference & .391 & .749 \\
\hline & ONO & $4.1(0.0-12.3)$ & & .648 & .391 & Reference & 1.000 \\
\hline & Combined & $2.9(1.2-15.5)$ & & .810 & .749 & 1.000 & Reference \\
\hline \multirow[t]{15}{*}{ LVESV (mL) } & $0 \mathrm{wk}$ & & & & & & \\
\hline & Sham & $29.0(25.5-34.9)$ & .651 & Reference & .915 & .411 & .471 \\
\hline & $\mathrm{OM}$ & $28.9(26.0-34.1)$ & & .915 & Reference & .540 & .337 \\
\hline & ONO & $26.1(22.3-31.5)$ & & .411 & .540 & Reference & .784 \\
\hline & Combined & $26.3(24.3-31.3)$ & & .471 & .337 & .784 & Reference \\
\hline & $4 \mathrm{wk}$ & & & & & & \\
\hline & Sham & $36.2(32.8-38.4)$ & .049 & Reference & .749 & .066 & .023 \\
\hline & $\mathrm{OM}$ & $36.4(31.5-41.1)$ & & .749 & Reference & .178 & .110 \\
\hline & ONO & $25.7(24.8-33.4)$ & & .066 & .178 & Reference & .235 \\
\hline & Combined & $22.1(19.8-31.4)$ & & .066 & .110 & .235 & Reference \\
\hline & Change of I & SV & & & & & \\
\hline & Sham & $6.8(1.0-8.6)$ & .128 & Reference & .749 & .171 & .174 \\
\hline & $\mathrm{OM}$ & $6.8(3.3-10.2)$ & & .749 & Reference & .111 & .110 \\
\hline & ONO & $1.1(-2.2-5.8)$ & & .171 & .111 & Reference & .235 \\
\hline & Combined & $-3.0(-7.2-2.5)$ & & .174 & .110 & .235 & Reference \\
\hline \multirow[t]{10}{*}{ LVEF (\%) } & $0 \mathrm{wk}$ & & & & & & \\
\hline & Sham & $34.7(31.9-35.8)$ & .831 & Reference & .593 & 1.000 & .574 \\
\hline & $\mathrm{OM}$ & $32.7(30.3-38.8)$ & & .593 & Reference & .903 & .748 \\
\hline & ONO & $33.0(30.2-45.2)$ & & 1.000 & .903 & Reference & .463 \\
\hline & Combined & $29.7(26.0-46.8)$ & & .574 & .748 & .463 & Reference \\
\hline & $4 \mathrm{wk}$ & & & & & & \\
\hline & Sham & $35.0(28.3-39.3)$ & .035 & Reference & .749 & .272 & .077 \\
\hline & $\mathrm{OM}$ & $35.5(30.2-37.3)$ & & .749 & Reference & .111 & .109 \\
\hline & ONO & $38.3(36.2-48.2)$ & & .272 & .111 & Reference & .410 \\
\hline & Combined & $51.5(35.4-58.2)$ & & .077 & .109 & .410 & Reference \\
\hline
\end{tabular}


TABLE E5. Continued

\begin{tabular}{|c|c|c|c|c|c|c|c|}
\hline \multirow[b]{2}{*}{ Variable } & \multirow[b]{2}{*}{ Group } & \multirow{2}{*}{$\begin{array}{c}\text { Median } \\
\text { (interquartile range) }\end{array}$} & \multirow[b]{2}{*}{$P$ value for trend } & \multicolumn{4}{|c|}{$P$ value for difference } \\
\hline & & & & Sham & OM & ONO & Combined \\
\hline & \multicolumn{7}{|c|}{ Change of LVEF } \\
\hline & Sham & $-0.25(-5.3-4.3)$ & .004 & Reference & .915 & .083 & .008 \\
\hline & $\mathrm{OM}$ & $0(-3.3-4.5)$ & & .915 & Reference & .111 & .014 \\
\hline & ONO & $5.0(3.0-6.2)$ & & .083 & .111 & Reference & .017 \\
\hline & Combined & $11.7(8.3-18.6)$ & & .008 & .014 & .017 & Reference \\
\hline
\end{tabular}

All $P$ values for trend were estimated by Kruskal-Wallis analysis, and $P$ value or difference were estimated by Mann-Whitney $U$ test. Sham, Saline alone group; $O M$, saline combined with pedicled omental flap group; ONO, saline-dissolved ONO-1301SR group; Combined, saline-dissolved ONO-1301SR combined with a pedicled omental flap group; $L V E D V$, left ventricular endodiastolic volume; $L V E S V$, left ventricular endosystolic volume; $L V E F$, left ventricular ejection fraction. 
TABLE E6. Details of Figure 6

\begin{tabular}{|c|c|c|c|c|c|c|c|c|}
\hline \multirow[b]{2}{*}{ Variable } & \multirow[b]{2}{*}{ Group } & \multirow{2}{*}{$\begin{array}{c}\text { Median } \\
\text { (interquartile range) }\end{array}$} & \multirow{2}{*}{$\begin{array}{l}P \text { value } \\
\text { for trend }\end{array}$} & \multicolumn{5}{|c|}{$P$ value or difference } \\
\hline & & & & Normal & Sham & OM & ONO & Combined \\
\hline \multirow{18}{*}{$\begin{array}{l}\text { Territorial circumferential } \\
\text { strain }(\%)\end{array}$} & LAD & & & & & & & \\
\hline & Normal & $-20.6(-26.3$ to $-13-4)$ & $<.001$ & Reference & $<.001$ & $<.001$ & .001 & .017 \\
\hline & Sham & $-5.4(-8.7$ to -3.1$)$ & & $<.001$ & Reference & .539 & .024 & .004 \\
\hline & $\mathrm{OM}$ & $-6.8(-8.8$ to -4.1$)$ & & $<.001$ & .539 & Reference & .103 & .015 \\
\hline & ONO & $-8.3(-15.1$ to -5.8$)$ & & .001 & .024 & .103 & Reference & .351 \\
\hline & Combined & $-12.2(-21.0$ to -6.3$)$ & & .017 & .004 & .015 & .351 & Reference \\
\hline & LCX & & & & & & & \\
\hline & Normal & $-19.8(-23.9$ to -17.6$)$ & .048 & Reference & .012 & .751 & .887 & .402 \\
\hline & Sham & $-16.0(-19.2$ to -9.6$)$ & & .012 & Reference & .330 & .022 & .018 \\
\hline & $\mathrm{OM}$ & $-18.2(-27.2$ to -12.3$)$ & & .751 & .330 & Reference & .597 & .363 \\
\hline & ONO & $-20.0(-23.6$ to -16.0$)$ & & .887 & .022 & .597 & Reference & .477 \\
\hline & Combined & $-23.9(-26.9$ to -14.2$)$ & & .402 & .018 & .363 & .477 & Reference \\
\hline & RCA & & & & & & & \\
\hline & Normal & $-19.9(-23.6$ to -14.4$)$ & .109 & Reference & .022 & .169 & .024 & .402 \\
\hline & Sham & $-14.6(-18.7$ to -9.8$)$ & & .022 & Reference & .459 & .950 & .248 \\
\hline & $\mathrm{OM}$ & $-14.7(-20.9$ to -13.5$)$ & & .169 & .459 & Reference & .262 & .657 \\
\hline & ONO & $-13.9(-19.0$ to -10.0$)$ & & .024 & .950 & .262 & Reference & .223 \\
\hline & Combined & $-16.4(-22.2$ to -12.4$)$ & & .402 & .248 & .657 & .223 & Reference \\
\hline \multirow{18}{*}{$\begin{array}{l}\text { Regional circumferential } \\
\text { strain }(\%)\end{array}$} & Infarct & & & & & & & \\
\hline & Normal & $-20.6(-26.3$ to -13.4$)$ & $<.001$ & Reference & $<.001$ & $<.001$ & .001 & .017 \\
\hline & Sham & $-5.4(-8.7$ to -3.1$)$ & & $<.001$ & Reference & .539 & .024 & .004 \\
\hline & $\mathrm{OM}$ & $-6.8(-8.8$ to -4.1$)$ & & $<.001$ & .539 & Reference & .103 & .015 \\
\hline & ONO & $-8.3(-15.1$ to -5.8$)$ & & .001 & .024 & .103 & Reference & .351 \\
\hline & Combined & $-12.2(-21.0$ to -6.3$)$ & & .017 & .004 & .015 & .351 & Reference \\
\hline & Border & & & & & & & \\
\hline & Normal & $-19.6(-23.4$ to -15.8$)$ & $<.001$ & Reference & $<.001$ & .049 & .030 & .420 \\
\hline & Sham & $-11.5(-15.9$ to -7.5$)$ & & $<.001$ & Reference & .112 & .018 & .003 \\
\hline & $\mathrm{OM}$ & $-15.7(-18.0$ to -11.9$)$ & & .049 & .112 & Reference & .780 & .300 \\
\hline & ONO & $-16.0(-18.5$ to -13.1$)$ & & .030 & .018 & .780 & Reference & .289 \\
\hline & Combined & $-18.0(-23.1$ to -13.1$)$ & & .420 & .003 & .300 & .289 & Reference \\
\hline & Remote & & & & & & & \\
\hline & Normal & $-20.5(-23.8$ to -19.0$)$ & .771 & Reference & .795 & .232 & .795 & .751 \\
\hline & Sham & $-20.9(-25.5$ to -15.5$)$ & & .795 & Reference & .298 & 1.000 & .885 \\
\hline & $\mathrm{OM}$ & $-24.1(-26.7$ to -19.6$)$ & & .232 & .298 & Reference & .335 & .375 \\
\hline & ONO & $-20.9(-23.0$ to -18.2$)$ & & .795 & 1.000 & .335 & Reference & .840 \\
\hline & Combined & $-20.4(-23.8$ to -19.0$)$ & & .751 & .885 & .375 & .840 & Reference \\
\hline \multirow{5}{*}{$\begin{array}{l}\text { Territorial circumferential } \\
\text { strain rate }\left(\mathrm{sec}^{-1}\right)\end{array}$} & LAD & & & & & & & \\
\hline & Normal & $-1.79(-2.60$ to -1.36$)$ & $<.001$ & Reference & $<.001$ & $<.001$ & $<.001$ & .002 \\
\hline & Sham & $-0.70(-0.94$ to -0.60$)$ & & $<.001$ & Reference & .553 & .477 & .052 \\
\hline & $\mathrm{OM}$ & $-0.88(-1.02$ to -0.60$)$ & & $<.001$ & .553 & Reference & .816 & .079 \\
\hline & ONO & $-0.80(-1.17$ to -0.54$)$ & & $<.001$ & .477 & .816 & Reference & .150 \\
\hline
\end{tabular}


TABLE E6. Continued

\begin{tabular}{|c|c|c|c|c|c|c|c|c|}
\hline \multirow[b]{2}{*}{ Variable } & \multirow[b]{2}{*}{ Group } & \multirow{2}{*}{$\begin{array}{c}\text { Median } \\
\text { (interquartile range) }\end{array}$} & \multirow{2}{*}{$\begin{array}{l}P \text { value } \\
\text { for trend }\end{array}$} & \multicolumn{5}{|c|}{$P$ value or difference } \\
\hline & & & & Normal & Sham & OM & ONO & Combined \\
\hline & Combined & $-1.12(-1.59$ to -0.68$)$ & & .002 & .052 & .079 & .150 & Reference \\
\hline & LCX & & & & & & & \\
\hline & Normal & $-2.09(-2.38$ to -1.57$)$ & .002 & Reference & $<.001$ & .006 & .002 & .060 \\
\hline & Sham & $-1.40(-1.53$ to -0.86$)$ & & $<.001$ & Reference & .751 & .517 & .091 \\
\hline & $\mathrm{OM}$ & $-1.21(-1.98$ to -0.81$)$ & & .006 & .751 & Reference & .899 & .169 \\
\hline & ONO & $-1.42(-1.80$ to -0.90$)$ & & .002 & .517 & .899 & Reference & .184 \\
\hline & Combined & $-1.53(-2.21$ to -1.36$)$ & & .060 & .091 & .169 & .184 & Reference \\
\hline & RCA & & & & & & & \\
\hline & Normal & $-1.64(-2.31$ to -1.30$)$ & $<.001$ & Reference & .013 & .002 & $<.001$ & .074 \\
\hline & Sham & $-1.34(-1.58$ to -0.91$)$ & & .013 & Reference & .434 & .085 & .527 \\
\hline & OM & $-1.17(-1.29$ to -0.91$)$ & & .002 & .434 & Reference & .374 & .220 \\
\hline & $\mathrm{ONO}$ & $-1.00(-1.22$ to -0.80$)$ & & $<.001$ & .085 & .374 & Reference & .129 \\
\hline & Combined & $-1.34(-1.78$ to -0.95$)$ & & .074 & .527 & .220 & .129 & Reference \\
\hline \multirow{18}{*}{$\begin{array}{l}\text { Regional circumferential } \\
\text { strain rate }\left(\mathrm{sec}^{-1}\right)\end{array}$} & Infarct & & & & & & & \\
\hline & Normal & $-1.79(-2.60$ to -1.36$)$ & $<.001$ & Reference & $<.001$ & $<.001$ & $<.001$ & .002 \\
\hline & Sham & $-0.70(-0.94$ to -0.60$)$ & & $<.001$ & Reference & .553 & .477 & .052 \\
\hline & $\mathrm{OM}$ & $-0.88(-1.02$ to -0.60$)$ & & $<.001$ & .553 & Reference & .816 & .079 \\
\hline & $\mathrm{ONO}$ & $-0.80(-1.17$ to -0.54$)$ & & $<.001$ & .477 & .816 & Reference & .150 \\
\hline & Combined & $-1.12(-1.59$ to -0.68$)$ & & .002 & .052 & .079 & .150 & Reference \\
\hline & Border & & & & & & & \\
\hline & Normal & $-1.74(-2.22$ to -1.50$)$ & $<.001$ & Reference & $<.001$ & $<.001$ & $<.001$ & .038 \\
\hline & Sham & $-1.09(-1.26$ to -0.83$)$ & & $<.001$ & Reference & .816 & .837 & .009 \\
\hline & $\mathrm{OM}$ & $-1.08(-1.31$ to -0.88$)$ & & $<.001$ & .816 & Reference & .882 & .054 \\
\hline & ONO & $-1.15(-1.31$ to -0.87$)$ & & $<.001$ & .837 & .882 & Reference & .016 \\
\hline & Combined & $-1.39(-1.88$ to -1.15$)$ & & .038 & .009 & .054 & .016 & Reference \\
\hline & Remote & & & & & & & \\
\hline & Normal & $-1.76(-2.20$ to -1.48$)$ & .277 & Reference & .665 & .177 & .046 & .112 \\
\hline & Sham & $-1.71(-2.17$ to -1.26$)$ & & .665 & Reference & .464 & .248 & .507 \\
\hline & $\mathrm{OM}$ & $-1.51(-1.75$ to -1.23$)$ & & .177 & .464 & Reference & .464 & .671 \\
\hline & ONO & $-1.38(-1.76$ to -1.00$)$ & & .046 & .248 & .464 & Reference & .603 \\
\hline & Combined & $-1.40(-1.74$ to -1.31$)$ & & .112 & .507 & .671 & .603 & Reference \\
\hline
\end{tabular}

All $P$ values or trend were estimated by Kruskal-Wallis analysis, and $P$ values for difference were estimated by Mann-Whitney $U$ test. Sham, Saline alone group; $O M$, saline combined with pedicled omental flap group; $O N O$, saline-dissolved ONO-1301SR group; Combined, saline-dissolved ONO-1301SR combined with a pedicled omental flap group; $L A D$, left anterior descending artery; $L C X$, left circumflex artery; $R C A$, right coronary artery. 
TABLE E7. Details of the histologic analysis

\begin{tabular}{|c|c|c|c|c|c|c|c|}
\hline \multirow[b]{2}{*}{ Variable } & \multirow[b]{2}{*}{ Groups } & \multirow{2}{*}{$\begin{array}{c}\text { Median } \\
\text { (interquartile range) }\end{array}$} & \multirow{2}{*}{$\begin{array}{l}P \text { value } \\
\text { for trend }\end{array}$} & \multicolumn{4}{|c|}{$P$ value for difference } \\
\hline & & & & Sham & OM & ONO & Combined \\
\hline \multirow[t]{4}{*}{ Myocardial fibrosis (\%) } & Sham & $24(14-29)$ & $<.001$ & Reference & .201 & .006 & .002 \\
\hline & $\mathrm{OM}$ & $17(15-22)$ & & .201 & Reference & .018 & .010 \\
\hline & ONO & $12(11-14)$ & & .006 & .018 & Reference & .464 \\
\hline & Combined & $11(8-14)$ & & .002 & .010 & .464 & Reference \\
\hline \multirow[t]{15}{*}{ Angiogenesis/arteriogenesis $\left(/ \mathrm{mm}^{2}\right)$} & \multicolumn{7}{|c|}{ CD31-positive capillaries } \\
\hline & Sham & $62(55-74)$ & $<.001$ & Reference & .563 & .008 & $<.001$ \\
\hline & $\mathrm{OM}$ & $66(62-73)$ & & .563 & Reference & .010 & .001 \\
\hline & ONO & $89(80-105)$ & & .008 & .010 & Reference & .203 \\
\hline & Combined & $98(88-118)$ & & $<.001$ & .001 & .203 & Reference \\
\hline & \multicolumn{7}{|c|}{ CD31-positive capillaries $(>100 \mu \mathrm{m})$} \\
\hline & Sham & $0.38(0.25-0.51)$ & $<.001$ & Reference & .195 & .001 & $<.001$ \\
\hline & $\mathrm{OM}$ & $0.57(0.24,1.01)$ & & .195 & Reference & .011 & .001 \\
\hline & ONO & $1.19(1.01-1.59)$ & & .001 & .011 & Reference & .295 \\
\hline & Combined & $1.50(1.11-1.71)$ & & $<.001$ & .001 & .295 & Reference \\
\hline & \multicolumn{7}{|c|}{ CD31/SMA-double positive arterioles } \\
\hline & Sham & $16(10-20)$ & $<.001$ & Reference & .354 & .177 & $<.001$ \\
\hline & $\mathrm{OM}$ & $18(13-22)$ & & .354 & Reference & .752 & .002 \\
\hline & ONO & $20(13-30)$ & & .177 & .752 & Reference & .023 \\
\hline & Combined & $31(26-35)$ & & $<.001$ & .002 & .023 & Reference \\
\hline \multirow[t]{4}{*}{ Myocyto size $(\mu \mathrm{m})$} & Sham & $21(19-23)$ & $<.001$ & Reference & .298 & .002 & $<.001$ \\
\hline & $\mathrm{OM}$ & $20(18-21)$ & & .298 & Reference & .014 & $<.001$ \\
\hline & ONO & $16(15-18)$ & & .002 & .014 & Reference & .263 \\
\hline & Combined & $16(15-17)$ & & $<.001$ & $<.001$ & .263 & Reference \\
\hline \multirow[t]{20}{*}{ Relative expression level/GAPDH } & \multicolumn{7}{|c|}{ Vascular endothelial cell growth factor } \\
\hline & Sham & $1.12(0.94-1.30)$ & .020 & Reference & .407 & .036 & .004 \\
\hline & $\mathrm{OM}$ & $1.59(0.86-1.86)$ & & .407 & Reference & .523 & .147 \\
\hline & ONO & $1.78(1.23-1.92)$ & & .036 & .523 & Reference & .319 \\
\hline & Combined & $1.84(1.42-2.36)$ & & .004 & .147 & .319 & Reference \\
\hline & \multicolumn{7}{|c|}{ Hepatocyte growth factor } \\
\hline & Sham & $0.86(0.66-1.19)$ & .357 & Reference & .591 & .262 & .751 \\
\hline & $\mathrm{OM}$ & $0.78(0.51-1.18)$ & & .591 & Reference & .125 & .239 \\
\hline & ONO & $1.17(0.89-1.82)$ & & .262 & .125 & Reference & .365 \\
\hline & Combined & $0.99(0.66-1.36)$ & & .751 & .239 & .365 & Reference \\
\hline & \multicolumn{7}{|c|}{ Basic fibroblast growth factor } \\
\hline & Sham & $0.43(0.16-0.84)$ & .034 & Reference & 0.928 & .205 & .030 \\
\hline & $\mathrm{OM}$ & $0.49(0.29-0.82)$ & & .928 & Reference & .160 & .037 \\
\hline & ONO & $0.75(0.63-0.87)$ & & .205 & .160 & Reference & .469 \\
\hline & Combined & $0.85(0.54-1.09)$ & & .030 & .037 & .469 & Reference \\
\hline & \multicolumn{7}{|c|}{ Stromal cell-derived factor 1} \\
\hline & Sham & $0.81(0.60-1.03)$ & .246 & Reference & .807 & .223 & .149 \\
\hline & $\mathrm{OM}$ & $0.83(0.45-1.00)$ & & .807 & Reference & .201 & .147 \\
\hline & ONO & $1.34(0.55-2.00)$ & & .223 & .201 & Reference & .717 \\
\hline & Combined & $1.04(0.70-1.71)$ & & .149 & .147 & .717 & Reference \\
\hline
\end{tabular}

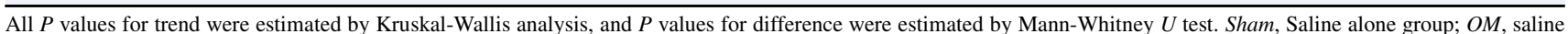
combined with pedicled omental flap group; ONO, saline-dissolved ONO-1301SR group; Combined, saline-dissolved ONO-1301SR combined with a pedicled omental flap group; GAPDH, glyceraldehyde-3-phosphate dehydrogenase. 
TABLE E8. Details of Figure E3

\begin{tabular}{|c|c|c|c|c|c|c|c|}
\hline \multirow[b]{2}{*}{ Variable } & \multirow[b]{2}{*}{ Group } & \multirow{2}{*}{$\begin{array}{c}\text { Median } \\
\text { (interquartile range) }\end{array}$} & \multirow{2}{*}{$\begin{array}{l}P \text { value } \\
\text { for trend }\end{array}$} & \multicolumn{4}{|c|}{$P$ value for difference } \\
\hline & & & & Sham & OM & ONO & Combined \\
\hline \multirow[t]{10}{*}{ Angiogenesis $\left(\mathrm{mm}^{2}\right)$} & \multicolumn{7}{|c|}{ CD31-positive capillaries } \\
\hline & Sham & $162(125-180)$ & .067 & Reference & .165 & .114 & .014 \\
\hline & $\mathrm{OM}$ & $184(150-195)$ & & .165 & Reference & .793 & .232 \\
\hline & ONO & $182(160-212)$ & & .114 & .793 & Reference & .512 \\
\hline & Combined & $196(165-219)$ & & .014 & .232 & .512 & Reference \\
\hline & \multicolumn{7}{|c|}{ CD31/SMA-double positive arterioles } \\
\hline & Sham & $128(104-138)$ & .092 & Reference & .232 & .070 & .026 \\
\hline & $\mathrm{OM}$ & $135(124-146)$ & & .232 & Reference & .372 & .375 \\
\hline & ONO & $146(128-160)$ & & .070 & .372 & Reference & .700 \\
\hline & Combined & $144(126-154)$ & & .026 & .375 & .700 & Reference \\
\hline \multirow{20}{*}{$\begin{array}{l}\text { Relative gene expression } \\
\text { level/GAPDH }\end{array}$} & \multicolumn{7}{|c|}{ Vascular endothelial cell growth factor } \\
\hline & Sham & $1.29(1.05-1.73)$ & .329 & Reference & .482 & .277 & .087 \\
\hline & $\mathrm{OM}$ & $1.51(1.12-1.84)$ & & .482 & Reference & .554 & .400 \\
\hline & ONO & $1.67(1.03-2.04)$ & & .277 & .554 & Reference & .556 \\
\hline & Combined & $1.57(1.13-2.75)$ & & .087 & .400 & .556 & Reference \\
\hline & \multicolumn{7}{|c|}{ Hepatocyte growth factor } \\
\hline & Sham & $0.82(0.46-1.15)$ & .457 & Reference & .591 & .262 & .751 \\
\hline & $\mathrm{OM}$ & $0.79(0.64-0.93)$ & & .591 & Reference & .125 & .239 \\
\hline & ONO & $0.80(0.60-1.18)$ & & .262 & .125 & Reference & .365 \\
\hline & Combined & $0.70(0.44-0.75)$ & & .751 & .239 & .365 & Reference \\
\hline & \multicolumn{7}{|c|}{ Basic fibroblast growth factor } \\
\hline & Sham & $0.33(0.23-0.52)$ & .098 & Reference & .074 & .833 & .051 \\
\hline & $\mathrm{OM}$ & $0.55(0.40-0.68)$ & & .074 & Reference & .208 & .808 \\
\hline & ONO & $0.37(0.21-0.73)$ & & .833 & .208 & Reference & .259 \\
\hline & Combined & $0.50(0.30-0.92)$ & & .051 & .808 & .259 & Reference \\
\hline & \multicolumn{7}{|c|}{ Stromal cell-derived factor 1} \\
\hline & Sham & $0.71(0.54-1.09)$ & .246 & Reference & .482 & .758 & .625 \\
\hline & $\mathrm{OM}$ & $0.86(0.54-1.42)$ & & .482 & Reference & .396 & .750 \\
\hline & ONO & $0.74(0.56-1.09)$ & & .758 & .396 & Reference & .625 \\
\hline & Combined & $0.76(0.55-1.17)$ & & .625 & .750 & .625 & Reference \\
\hline
\end{tabular}

All $P$ values for trend were estimated by Kruskal-Wallis analysis, and $P$ values for difference were estimated by Mann-Whitney $U$ test. Sham, Saline alone group; $O M$, saline combined with pedicled omental flap group; ONO, saline-dissolved ONO-1301SR group; Combined, saline-dissolved ONO-1301SR combined with a pedicled omental flap group; SMA, smooth muscle antibody; GAPDH, glyceraldehyde-3-phosphate dehydrogenase. 